\title{
The Role of Dopamine in Locomotor Activity and Learning
}

\author{
RICHARD J. BENINGER \\ Department of Psychology, Queen's University, Kingston K7L 3N6 (Canada) \\ (Accepted May 10th, 1983) \\ Key words: dopamine - locomotor activity — learning — incentive learning — reinforcement — basal ganglia — acetylcholine — \\ adenylate cyclase - synaptic modulation - neuroleptics - schizophrenia
}

\section{CONTENTS}

1. Introduction

2. DA and locomotor activity

3. DA and learning

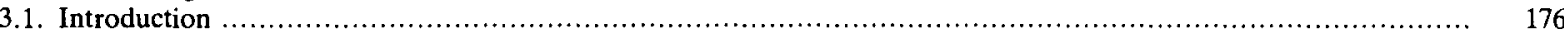

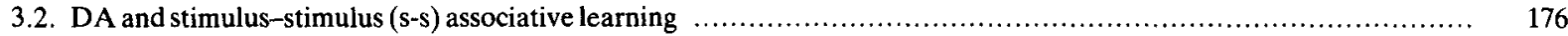

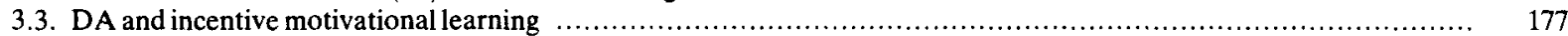

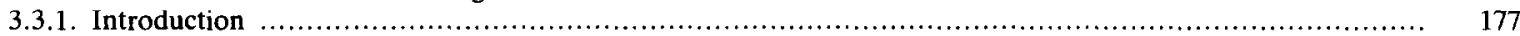

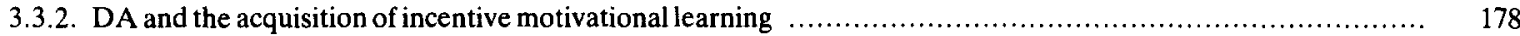

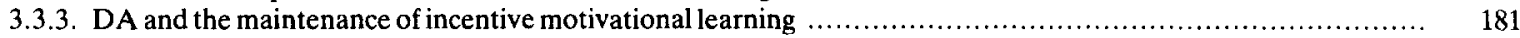

4. Summary

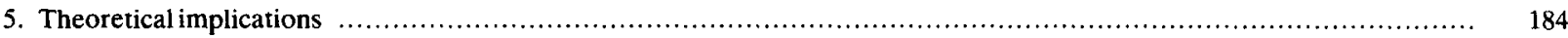

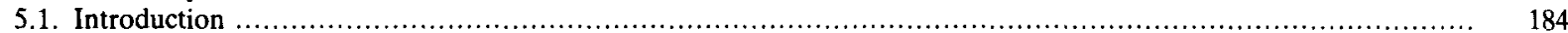

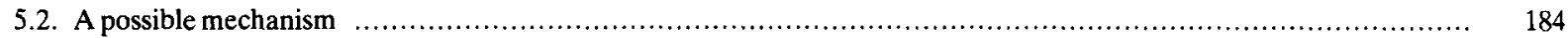

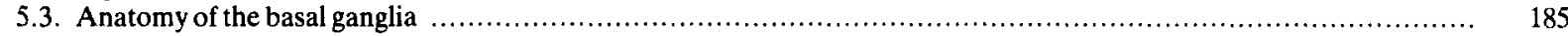

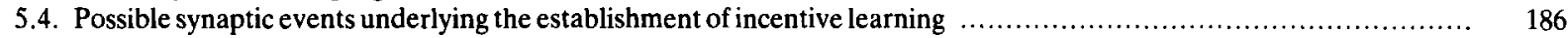

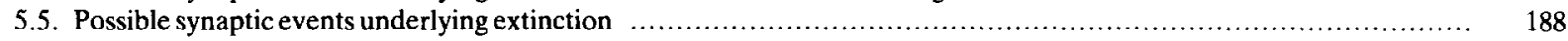

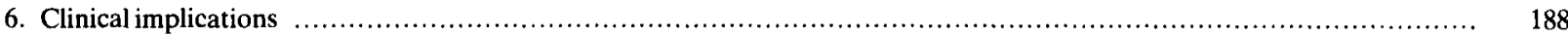

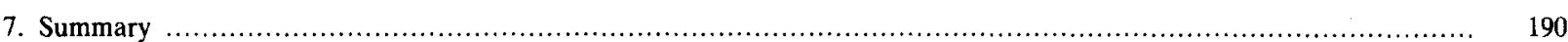

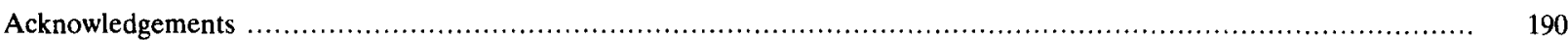

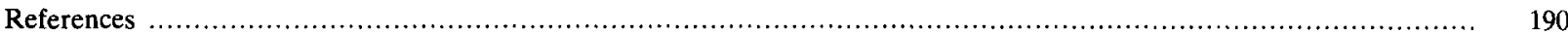

\section{INTRODUCTION}

Since dopamine (DA) was first identified in the central nervous system (CNS) 25 years ago ${ }^{29}$ enormous strides have been made towards understanding the anatomy, behavioral function and clinical importance of neurons utilizing this chemical as a transmitter substance. The loci of cell bodies containing DA and the areas to which they project their axons now have been described in considerable detail114,115. As reviewed below, the role of DA systems in behavioral phenomena including locomotor activity and vari- ous forms of learning continues to be the topic of a large number of scientific investigations. The value of this intense research activity is underscored by growing evidence implicating abnormal DA function in patients with neuropsychiatric disorders including Parkinson's disease ${ }^{85}$ and schizophrenia ${ }^{108,120,177,196}$ Some recent findings provide indirect evidence that the underlying abnormality in children suffering from attention deficit disorder with hyperactivity also may be dopaminergic ${ }^{171}$. Furthermore, drugs of abuse, including cocaine and amphetamine, are known to enhance DA transmission in the brain ${ }^{164}$. Taken togeth- 
er, these findings indicate considerable need for establishing the behavioral functions of DA.

This article contains a review of the behavioral studies that provide clues to the function of DA; it will be shown that the results suggest a specific role for DA neurons in locomotor activity and particular learning processes. This is followed by a consideration of the theoretical and clinical implications of behavioural studies of DA function; in this last section it will be shown that specific insights into appropriate treatments of clinical populations suffering from abnormalities of DA function can be drawn from these studies.

A wide range of procedures has been employed in behavioral studies of DA function ${ }^{42,60,162,199,200}$. These experiments can be separated into two broad categories based on the phenomena studied: those concerned primarily with locomotor activity; and those involving a possible role for DA in learning processes. As reviewed below, it appears that DA is importantly involved in both locomotor activity and some forms of learning. Because of this dual role for DA and the fact that learning usually is assessed with behavioral dependent measures, some learning stud. ies may have been confounded by the effect of DA manipulations on locomotor activity.

\section{DA AND LOCOMOTOR ACTIVITY}

The effects of manipulations of DA systems on unconditioned behavior have been reviewed by several authors ${ }^{42,194}$. It repeatedly has been found that global interventions that decrease activity in all DA systems of adult animals produce hypoactivity. Thus, locomotor activity is reduced by $\mathrm{DA}$ receptor blocking drugs $^{2}$, bilateral 6-hydroxydopamine (6-OHDA) or electrolytic lesions of ascending DA systems or drugs such as reserpine and $\alpha$-methyl- $p$-tyrosine that deplete catecholamines 29.194 . Drugs that enhance transmission at DA synapses, on the other hand, increase locomotor activity or produce stereotypy depending on the dose66.118; these stimulant effects are produced by $\mathrm{D}$-amphetamine, apomorphine, cocaine, L-dihydroxyphenylalanine (I-DOPA) and numerous similarly acting drugs $34,38,90$.

Many researchers have been concerned with the possible contribution of individual DA nuclei or terminal areas to locomotor activity. It has been sug- gested that the nigrostriatal DA pathway is involved in locomotion. Thus, bilateral 6-OHDA lesions of the substantia nigra ( $\mathrm{SN}$ ) that produce extensive $(>90 \%$ ) depletion of striatal DA result in severe hypokinesia ${ }^{123}$; however, the lesions in this study were extensive and may have affected non-striatal DA as well. Similarly, the observation that patients suffering from Parkinson's disease, characterized by rigidity of the limbs and hypokinesia, undergo degeneration of the nigrostriatal DA neurons ${ }^{85}$ also might implicate this system in locomotor functioning. Howev$\mathrm{er}$, these results cannot be viewed as conclusive since some deficits of non-striatal DA also have been found in post-mortem brain tissue from Parkinsonian patients ${ }^{56}$.

The mesolimbic-mesocortical DA neurons also have been implicated in locomotor activity but their role remains equivocal. Thus, it has been reported that bilateral 6-OHDA lesions of the origin of these neurons, the ventral tegmental area (VTA) results in no change in locomotion, decreased locomotion and others have reported an increase $63,104,109$. One possibility is that this discrepancy arose because of partial damage to VIA DA neurons in some studies, an interpretation supported by the finding that large 6.OHDA lesions of VTA produced hypoactivity whereas smaller lesions resulted in hyperactivityl104. Alternatively, conflicting data may have been reported because the DA cells originating in VTA are not uniformly involved in locomotion; whereas bilateral 6-OHDA lesions of the limbic terminal regions, nucleus accumbens and olfactory tubercle result in decreased locomotor activity ${ }^{91,103}$, similar lesions of the frontal cortical DA terminal area produce hyperactivity ${ }^{31}$. This latter finding is corroborated by the observation of a high positive correlation between the level of decrease in frontal cortical DA resulting from electrocoagulation of the VTA and increased locomotion ${ }^{186}$. Further, studies employing localized injections of DA or DA agonists into the nucleus accumbens report hyperactivity $4,39,41,50,92,143,144,197$. Taken together, these findings may indicate that the DA neurons projecting to basal forebrain areas, viz., caudate, putamen, nucleus accumbens, and olfactory tubercle, enhance locomotor activity whereas mesocortical DA neurons normally inhibit locomotion.

The results of a number of recent studies seem to suggest that mesolimbic and nigrostriatal DA neu- 
rons mediate different components of the behavioral syndrome produced by DA agonists. Thus, mesolimbic DA neurons may be primarily involved in increased locomotion produced by DA agonists such as $\mathrm{D}$-amphetamine and apomorphine; nigrostriatal DA neurons, on the other hand, may be more involved in stereotyped licking, biting and gnawing produced by high doses of these compounds ${ }^{66,118}$. In support of this hypothesis, it has been reported that disruption of DA function in the caudate nucleus decreases D-amphetamine-stimulated stereotyped behavior without affecting locomotion produced by this drug 43,99 . 144 whereas similar manipulations of the nucleus accumbens disrupt locomotion stimulated by DA agonists ${ }^{107.144}$. Thus, the nucleus accumbens and striatum might mediate different aspects of behavior stimulated by DA agonists. However, Costall and Naylor ${ }^{42}$ have cautioned that this distinction is not complete; they point out that it is possible to produce hyperactivity with intrastriatal injections of $\mathrm{DA}^{40}$ and, conversely, it is possible to produce stereotypy with intra-accumbens injections of DA agonists. Furthermore, it now is clear that some VTA DA neurons terminate in striatal areas including the anteromedial part of the caudate nucleus 173 and some nigral DA neurons may project to non-neostriatal regions 55 . Therefore, the functional distinction between the limbic and striatal DA systems remains in question.

Some researchers have emphasized the sensory rather than motor impairments resulting from damage to the nigrostriatal system. Rats undergoing a unilateral 6-OHDA lesion of SN were tested for orientation responses to mild somatosensory stimulation of specific areas of the body surface. Although showing well-localized orientation responses to touch stimuli ipsilateral to the lesion, there was a marked lack of orientation to somatosensory stimuli presented to the contralateral side of the bodyl21. The complementary effect follows unilateral intrastriatal injections of DA, these rats showing enhanced responsiveness to stimuli presented to the side contralateral to the injection ${ }^{94}$. These results suggest that DA may normally play a role in mediating an animal's level of responsiveness to sensory stimulation.

The apparent sensory neglect probably is not attributable to a motor deficit, i.e. a simple inability to organize a required response. This was shown by in- vestigating the ability of a light stimulus to produce conditioned suppression of licking in $\mathrm{SN}$-lesioned cats; whereas onset of a cue light located in the visual field ipsilateral to the lesion produced lick suppression comparable to that seen in control animals, the same stimulus presented on the contralateral side failed to produce the effect. As the lesioned cats clearly were capable of performing the conditioned response, it was suggested that sensory input to the side contralateral to the lesion failed to engage normal responses ${ }^{57}$. In a similar vein, it has been argued that unilateral 6-OHDA lesions of SN do not result in sensory neglect through a sensory defecit, i.e. a simple inability to perceive the stimulus. This suggestion was based on the observation that unilateral SN-lesioned and sham operated rats relearned a visual discrimination at similar rates even though the eye ipsilateral to the lesion was occluded. The authors concluded that the contralateral (neglected) eye $\because$. does see and is adequately used for control of locomotion .... They concluded that sensory neglect is observed because stimuli contralateral to DA denervation fail to arouse the animal172. If arousal is tantamount to engaging normal responses, then these arguments are similar. It can be concluded that the apparent contralateral sensory neglect seen in animals with unilateral damage to $\mathrm{SN}$ is not the result of impaired processing of sensory input; rather, these animals appear to be deficient in their ability to interface sensory input onto response systems. A recent study of the effects of DA receptor blocking drugs on classical conditioning similarly suggested that these compounds reduce the excitatory (response eliciting) properties of sensory stimuli ${ }^{74}$.

From the studies reviewed above, it seems clear that animals undergoing extensive damage to the brain's DA systems evidence a marked impairment in locomotor activity. Numerous studies have shown, however, that these hypokinetic animals retain the ability to perform complex motor sequences; this can be demonstrated by presenting intense (aversive) stimuli. Thus, neuroleptic-treated rats that fail to avoid electric shocks during a warning stimulus readily escape when shock is presented 16,17. DA-depleted rats that are hypokinetic and hyporesponsive to sensory stimuli show a reversal of this deficit when placed in cold water, an ice bath or among either rats or cats ${ }^{122,183,187}$. A similar phenomenon is observed in 
Parkinsonian patients; normally hypokinetic, these patients have been observed to locomote with apparent ease when confronted with potentially dangerous situations ${ }^{168,169}$. Taken together, these observations suggest that animals with DA function disrupted are not unable to perform complex responses per se. They are deficient in their ability to engage response systems except under intense stimulus situations.

\section{DA AND LEARNING}

\subsection{Introduction}

There has been considerable interest in possible roles for DA neurons in learning processes. Although there are many forms of learning ranging from simple habituation to the learning of complex motor sequences, in this review only two types of learning will be distinguished $23,25,151$. One is stimulus-stimulus associative learning that occurs when stimuli are presented in close temporal contiguity (although there are exceptions ${ }^{70}$ ). The other is incentive motivational learning that involves a change in the ability of neutral stimuli to elicit operant responses; this form of learning occurs when biologically important stimuli are encountered. DA seems to be involved in this latter type of learning but not the former. Evidence supporting this position is discussed separately for each type of learning.

\subsection{DA and stimulus-stimulus (s-s) associative learning}

From the preceding discussion of the role of DA in locomotor activity, it is clear that any behavioural test of the possible contribution of DA systems to learning processes must control for these motor effects. One approach has been to present neuroleptictreated rats with stimulus pairings and then to test for associative learning in subsequent drug-free sessions. Using this approach it was shown that rats that received tone-shock pairings while under the influence of a large dose of the DA receptor blocker, chlorpromazine learned the s-s association as evidenced by largely autonomic conditioned emotional responses (CER) ${ }^{86}$. When neuroleptic-treated rats were exposed to one way shock avoidance sessions in which a tone signaled shock, they failed to learn to avoid; when subsequently tested while lever pressing for food in an undrugged state, however, these rats showed the CER to the tone indicating that they had learned the s-s association ${ }^{16}$. Similar results have been obtained employing the defensive burying paradigm; burying apparently is a highly complex unconditioned response directed toward aversive environmental stimuli145. Rats received pairings of a wallmounted prod with electric shock while treated with the DA receptor blocker, pimozide; when subsequently tested for prod burying when undrugged these rats buried as much as control rats that received prod-shock pairings while undrugged 15 . Thus, they learned the association of the prod with shock while in the drug state. In another study, when neuroleptictreated rats were pre-exposed to a maze and then observed subsequently when in a drug free state evidence of latent learning was seen, indicating that s-s associative learning had occurred while the rats were drugged ${ }^{1}$. The observation of transfer from classical conditioning to operant discrimination learning even though rats were under the influence of a high dose of pimozide during the classical tone-food pairings ${ }^{19}$ further supports the suggestion that s-s associative learning can occur in animals with DA function disrupted.

A number of experiments have looked at the effects of neuroleptics on the accuracy of an established discrimination in testing a possible role for DA in s-s associative learning. It has been found that although pimozide produces a dose-dependent decrease in operant responding, it fails to affect the accuracy of a simultaneous or successive discrimination ${ }^{8,189,191}$. The DA receptor blocker, haloperidol has been reported to be without effect on short-term memory $y^{6}$ further suggesting that s-s associative learning may be independent of DA; however, conflicting results have been reported 135 . In a recent study it was found that pimozide was without effect on the accuracy of an identity matching to sample task but interfered with symbolic matching in the same pigeons ${ }^{184}$. Others have found that rats or monkeys receiving 6-OHDA VTA ${ }^{174}$ are frontal cortical lesions ${ }^{27}$, respectively, show no impairment in a well-trained visual discrimination but are deficient in their ability to perform a delayed alteration task. These findings may indicate DA involvement in the maintenance of highly complex tasks requiring elaborate s-s associative 
mechanisms; further work is needed to test this possibility.

At the end of Section 2, results were reviewed showing that animals with brain DA function disrupted, although hypokinetic under normal circumstances, can be induced to move when confronted with intense stimulation. Some experimenters, taking advantage of this fact, have trained DA-disrupted animals in electrified or underwater mazes and demonstrated that they can learn to choose the correct path. Thus, it was shown that animals with bilateral 6-OHDA lesions of the nigro-striatal pathway could learn a brightness discrimination in an electrified Y-maze as well as controls ${ }^{148}$. On the other hand, it has been reported that the underwater swim maze brightness discrimination learning of rats was blocked by the neuroleptic, spiroperidol149. However, as discussed elsewhere ${ }^{16}$, the data from this study do not agree with the authors' conclusions. Animals were required to swim to the dark area of the underwater maze, a choice contrary to their natural tendency to seek a lighted area; consequently, initial error rates were about $70-80 \%$. Spiroperidol-treated rats were observed to improve in this task, albeit more slowly than controls, to an error rate of about $40 \%$ by session 4 , the last test session. Although these drugged animals were not performing significantly better than chance by session 4 , they appeared to be showing a learning curve. Possibly the slower rate of learning in these animals was related to motor impairments produced by spiroperidol, but they did seem to be learning. The data from a second paper by the same authors in which they conclude that 6-OHDA-produced DA denervations block the acquisition of both brightness and spatial discriminations in the underwater maze ${ }^{150}$ are subject to the samc criticism. In addition, the DA denervations in some of these animals were so complete that even the threat of drowning was only able to induce a low level of responding. When the unwarranted conclusions from these experiments are recognized, it can be seen that studies employing intense stimulation to overcome hypokinesia in DA-disrupted animals support the hypothesis that DA neuronal function may not be required for s-s associative learning to occur.

\subsection{DA and incentive-motivational learning}

\subsubsection{Introduction}

A number of learning theorists have proposed a two (or more) process learning scheme somewhat similar to the one that will be developed here $23,25,151$. It is not the purpose of this review to compare and contrast various theoretical treatments of learning. Although the terms employed here are used by many theorists, their use does not necessarily imply the meaning given them by others; each is used according to the definitions and scheme described in the next paragraphs.

Stimuli that are biologically important to animals are defined as reinforcers or, in the case of aversive stimuli that cause pain and tissue damage, punishers. Implicit in this definition is the assumption that when an animal encounters a biological significant stimulus, that stimulus will elicit appropriate consummatory responses. Alternative terms for reinforcer include primary incentive stimulus and reward. The presentation of a primary incentive stimulus is defined as positive reinforcement and the termination of a punisher is defined as negative reinforcement. The consequences of the reinforcement event are a change in the operant response-eliciting ability of neutral environmental stimuli associated with reinforcement ${ }^{24}$. These changed stimuli are termed conditioned incentive motivational stimuli; it will be argued that DA is involved in this type of learning. Note that when a primary incentive stimulus, for example food to a food-deprived animal, is presented, two types of learning are possible according to this scheme. One is s-s learning, involving the association of environmental stimuli with sensory aspects of the food such as taste, odor, texture, appearance and sound that may occur independent of DA functioning; the other is incentive motivational learning that would involve a change in the ability of these environmental stimuli to elicit operant responses in the future and may require DA to occur.

It should be noted that this formulation of the role of reinforcement in learning avoids the use of terms such as hedonia or pleasure, that are descriptive of certain mental states. Some theorists include these states along with stimuli, such as taste and smell, as part of the stimulus aspects of food 200 . For these theorists, the statement that s-s associative learning oc- 
curs independent of DA functioning may seem erroneous. This is because the association of pleasure, a stimulus aspect of food, with environmental stimuli fails to occur in animals with DA function disrupted. However, to draw the conclusion that blockade of DA neurotransmission produces anhedonia (i.e. blocks the pleasurable aspects of reinforcement), it is necessary to observe behavior. Thus, environmental stimuli associated with reinforcement lose their ability to elicit operant responses when DA neuronal function is blocked; from this it is inferred that pleasure no longer occurs. The present formulation makes a distinction between the sensory, as opposed to the operant response eliciting aspects of reinforcing stimuli. These latter aspects of reinforcing stimuli, termed here incentive motivational, may or may not produce mental states described as hedonic or pleasurable. Nevertheless, they seem to require intact DA functioning to become associated with environmental stimuli.

The nature of the operant response elicited by conditioned incentive motivational stimuli requires comment. Historically, incentive theory arose because the older, more rigid, stimulus-response connectionistic notions of the effects of reinforcement on behavior were shown to be inadequate $23,25,119$. Instead, it was suggested that stimuli associated with reinforcement become conditioned sources of motivation, eliciting increases in general activity. More molecular analyzes of this notion of conditioned incentive motivation have shown it, too, to have inadequacies ${ }^{119}$. Recent theories emphasize the learning of stimulus-reinforcement and response-reinforcement associations; these associations give rise to expectancies that direct behavior ${ }^{25,119}$. What the present analysis of DA's role in learning suggests is that the association of the stimulus aspects of reinforcement with environmental stimuli can occur without those stimuli acquiring the ability to effect responding; as discussed in the preceding section, this situation arises in animals undergoing conditioning trials when DA synaptic transmission is blocked. Although the precise nature of the influence of incentive conditioning on operant response systems remains to be worked out, it seems clear that the association of environmental stimuli with the stimulus aspects of reinforcement and the acquisition by environmental stimuli of the ability to elicit responding are distinct processes mediated by different neurotransmitter systems.

Studies of the role of DA in incentive motivational learning can be organized into two broad categories; the first is the effect of manipulations of DA functioning on the establishment of this type of learning and the second is the effects of altered DA neurotransmission on the maintenance of incentive conditioning established prior to testing. Most studies fall into the second category.

\subsubsection{DA and the acquisition of incentive motivational learning}

When the effects of the DA receptor blocker, pimozide on the acquisition of lever pressing for food were tested, dose-related attenuation of learning was seen $^{201}$. Although this finding is consistent with the hypothesis that normal DA functioning is required for stimuli associated with the test environment to acquire incentive motivational properties that enable them to elicit responding, it is not possible to rule out the effects of drug induced motor impairments. A conditioned reinforcement procedure can be used to avoid this confound. This technique involves first pairing a primary incentive stimulus (e.g. food) with a neutral stimulus (e.g. tone) so that the neutral stimulus becomes a conditioned incentive motivational stimulus; in subsequent test session with two levers, this incentive learning can be measured as an increase in the proportion of responses on the lever that produces the conditioned stimulus (i.e. tone). With this procedure, drugs can be administered during the incentive conditioning phase when the only response requirement is that the animals eat the food; then the test for incentive learning is carried out when the animals are undrugged. It was found dat pimozide during the conditioning phase blocked the establishment of incentive learning ${ }^{18}$. Using intravenous injections of DA agonists as the primary incentive stimulus in a similar procedure others have shown that incentive learning is blocked by the neuroleptic, haloperidol 47,48 . These findings provide support for the hypothesis that DA is required for incentive learning to occur. It is noteworthy that in the studies of conditioned reinforcement based on food, although the previously drugged rats showed no evidence of incentive learning, they should have learned the association between the tone and the sensory 
properties of the food; support for this conclusion was found in a transfer study referred to in the preceding section ${ }^{19}$. With regard to these different types of learning, mention should be made of the possibility that neuroleptic treatment during pairings of a buzzer with intravenous injection of a DA agonist might block both the primary incentive and sensory properties of the agonist. The observed blockade of learning could be due to either of these effects. Therefore, the latter conditioned reinforcement findings do not provide unequivocal support for the hypothesis that DA mediates incentive learning but they are consistent with the results of studies employing food as the primary incentive stimulus.

A group of studies that can be viewed as involving incentive conditioning are those that show a placebo effect in animals previously injected with a DA agonist such as D-amphetamine or cocaine. Basically, these studies involve injecting animals with the drug and placing them in a test environment on a series of trials; then vehicle is injected and the locomotor activity of the previously drugged group is compared to that of a control group that has had a similar drug history but has not been drugged in the test environment. Results show that animals previously receiving amphetamine or cocaine in the test environment are more active than controls on the vehicle test day $11,84,89,142,147,160,188$. These findings are consistent with the hypothesis that DA mediates incentive motivational learning. Thus, animals previously treated with DA agonists in the test environment undergo incentive learning resulting in an increase in the ability of those stimuli to elicit responding.

Before turning to the studies concerning the effects of disruption of DA functioning on behaviors conditioned prior to drug treatment, the effects of DA disruptions on the acquisition of avoidance responding will be considered. As defined above, reinforcement in the avoidance situation occurs when shock is terminated; presumably, this event results in increased activity in DA neurons that alters the ability of recently encountered environmental stimuli (e.g. a door that signals safety, apparatus stimuli associated with safety) to elicit operant responses. The recent observation, using in vivo voltammetry, of increased DA release in the striatum following brief electric shock to the tail ${ }^{98}$ provides indirect support for this suggestion that DA mediates negative re- inforcement (see also ${ }^{3,167}$ ). If DA function is blocked during training of this task, avoidance responding should fail to occur; however, since intense stimulation can overcome hypokinesia in these animals, escape responding should continue to be observed. In support of this analysis, it has been reported that animals fail to acquire avoidance responses (although continuing to escape) if trained after DA-depleting intracisternal injections of 6-OHDA, intranigral injections of 6-OHDA or injection with DA receptor blockers 16,17,36,37,46,61,62,146,209. Again, it is important to note that although avoidance responses fail to occur, s-s associative learning should be intact; thus, the relationship between the pre-shock stimuli and shock is learned by these DA-disrupted animals as evidenced by apparent fear-indicating autonomic responses such as defecation and squealing during the preshock period ${ }^{146}$ and by CER tests ${ }^{16}$.

At this point, the lack of symmetry between the effects of decreased DA function on aversive and appetitive conditioning requires comment. As just mentioned, when animals with disrupted DA function receive tone-shock pairings, although failing to avoid, they learn the association between these stimuli; it is noteworthy that the shock retains its aversive qualities under conditions of impaired DA transmission and that the tone acquires these aversive qualities. If the animal subsequently is tested while not drugged and in the absence of shock, the acquired aversive nature of the tone can be demonstrated by the acquisition of avoidance learning ${ }^{17}$. This shows that even conditioned aversive stimuli established under the influence of a DA receptor blocker can subsequently act in their own right as negative reinforcers when DA function is unimpaired. When a DA disrupted animal receives tone-food pairings, it too learns the association of these stimuli ${ }^{19}$. However, when this rat is undrugged and tested for lever-press acquisition in the absence of food, the tone fails to act as a conditioned appetitive reinforcer ${ }^{18}$. This observation might suggest that the DA antagonist had blocked the appetitive nature of food; however, the fact that food was eaten during conditioning argues against this possibility. It seems, therefore, that conditioned appetitive stimuli established under the influence of a DA receptor blocker, unlike similarly established conditioned aversive stimuli, cannot act subsequently as reinforcers in their own right. Thus, the effects 
of DA blockers on appetitive and aversive conditioning are asymmetrical insofar as they appear to block the subsequent ability of a conditioned appetitive stimulus to (positively) reinforce but not the ability of a conditioned aversive stimulus to (negatively) reinforce.

Another subset of studies falls into the broad category of those testing the effects of DA manipulations on the acquisition of learning. These involve the effects of enhanced DA activity on learning to withhold a punished stepdown response. This task involves learning to remain on a platform suspended above an electrified grid floor; normally, curious animals when placed on the platform will step down. This response produces punishment in the form of electric footshock. The response of returning to the platform is negatively reinforced by the offset of the punishing stimulus. In subsequent tests, learning is demonstrated by an increased tendency to remain on the platform, the stepdown latency being longer. A number of researchers have shown that memory for this task is impaired (retrograde amnesia) by electrical stimulation of the cell bodies in $\mathrm{SN}$ during training and that the disruption depends on $\mathrm{DA}^{59,140,161.162}$. The disruption of learning may be understood with reference to extraneous or inappropriate incentive learning; thus, stimuli, for example, those associated with parts of the apparatus other than the platform, that normally would remain neutral may have become conditioned incentive stimuli bccausc of activation of DA neurons during training. In retest sessions, animals may have failed to remain on the platform because this learning resulted in inappropriate approach responses to stimuli that normally would have been neutral.

The results of an experiment investigating the effects of the DA agonist, apomorphine on latent learning can be interpreted in a similar manner to the stepdown data. It is well established that animals preexposed to an unbaited maze run that maze with fewer errors when subsequently trained to traverse it for food; this phenomenon has been termed latent learning ${ }^{119}$. As discussed in Section 3.2, this type of learning has been found to be unaffected by treatment with DA receptor blockers during pre-exposure ${ }^{1}$, suggesting that $\mathrm{s}-\mathrm{s}$ associative learning occurs independent of DA function. In the same study, it was reported that rats pre-exposed to the maze while treated with apomorphine subsequently were impaired. As in the case of the stepdown task, this disruption of learning may be attributable to inappropriate incentive conditioning. Thus, during pre-exposure, maze stimuli, for example those associated with blind alleys, may have become incentive stimuli in the apomorphine-treated animals. In subsequent tests of maze learning these rats made more errors, possibly because of this inappropriate incentive conditioning. This interpretation must be viewed with caution, however, since other possibilities, for example, state dependent learning effects, were not evaluated in this study.

Two recent studies reported findings that may be directly relevant to the preceding interpretation of the results of punished stepdown and latent learning experiments. These studies employed a latent inhibition procedure to evaluate the effects of enhanced DA activity on animals' ability to learn to ignore irrelevant stimuli. This approach involved first a series of non-reinforced presentations of a neutral stimulus (e.g. tone) and then conditioning trials using that stimulus to signal reinforcement; latent inhibition is evidenced by a retarded acquisition in pre-exposed animals. In two well-controlled studies it was found that animals with enhanced activity in DA systems during the pre-exposure phase failed to show latent inhibition; DA activity was stimulated in rats by D-amphetamine injections, haloperidol-induced supersensitivity or intraaccumbens D-amphetamine ${ }^{180,181}$. It also was found that microinjections of D-amphetamine into the caudate-putamen failed to antagonize the latent inhibition effect ${ }^{18}$. The authors interpreted their results as possibly implicating DA systems in learning to ignore irrelevant stimuli. According to the present formulation, enhanced DA activity during pre-exposure to the neutral stimulus may have resulted in that stimulus becoming (inappropriately) a conditioned incentive stimulus. When it subsequently was used to signal reinforcement, retarded acquisition was not observed possibly because of this incentive learning. If this interpretation is correct, then these latent inhibition data are consistent with the punished stepdown and latent learning results already discussed.

In summary, incentive learning seems to fail to occur in animals undergoing acquisition training while DA function is blocked. This has been observed in 
tests of lever-press acquisition, conditioned reinforcement and avoidance learning. On the other hand, enhanced DA activity produced by treatment with stimulant drugs such as D-amphetamine or cocaine results in incentive learning leading to environment-specific conditioned locomotor activity. However, incentive learning resulting from enhanced DA activity may impair the apparent memory of other tasks. This was suggested by the effects of stimulating DA neurotransmission in punished stepdown, latent learning and latent inhibition experiments.

\subsubsection{DA and the maintenance of incentive motiva- tional learning}

Turning now to the second broad category of studies of the role of DA in incentive learning, the following paragraphs discuss the effects of manipulations of DA neurotransmission on the maintenance of incentive conditioning established prior to testing. There are many more studies in this category than in the previous one and a number of excellent reviews of this laterature have appeared $60,199,200$. The effects of DA disruption on well-trained positively-reinforced lever press responding, stimulant produced environment-specific conditioned activity and negatively reinforced shuttle responding will be considered. It will be suggested that animals well-trained in operant tasks involving reinforcement can continue to respond for a time when DA function has been blocked. However, with more extensive testing in the absence of normal DA neurotransmission, even the responding of well-traincd animals ceases.

Wise et al. ${ }^{202,203}$ trained animals to respond on a continuous reinforcement schedule for food and then examined the effects of pimozide over several test sessions. They found that pimozide-treated animals showed a progressive decline in responding from session to session similar to extinction and concluded that pimozide blocks the effects of reinforcement. The use of repeated testing was an important feature of these studies since a simple attenuation of responding in the first test session could be interpreted as a drug-induced motor impairment; however, a stepwise session to session decline in responding cannot be attributed simply to a motor impairment especially since control studies ruled out cumulative toxicity of repeated dosing with pimozide as a possible explanation of the effect. The finding that pimozide produces an extinction-like session to session decline in food-reinforced responding has been replicated several times $8,71,72,124,190,192$.

One exception to these findings is the effect of DA disruption on responding differentially reinforced for low rates (DRL). It was reported that DRL responding was not affected by pimozide over 3 test sessions $^{124}$ or by 6-OHDA-produced DA depletions ${ }^{111}$. However, the pimozide-treated rats were maintained on a lean feeding schedule; this variable and the low response demands of DRL schedules may account for the lack of effect of pimozide. Support for this hypothesis was shown when it recently was found that animals kept under high levels of food deprivation were less affected than more moderately deprived animals by high doses of neuroleptics ${ }^{20}$. The lack of effect of 6-OHDA on DRL behavior may be attributable to subtotal DA depletions; indeed, the authors cite preliminary findings from 6-OHDAtreated animals more severely depleted of DA supporting this interpretation ${ }^{111}$. It appears, therefore, that a case can be made for concluding that the incentive conditioning properties of food are blocked when DA function is blocked.

There has been some controversy surrounding the contribution of motor impairments to the neuroleptic extinction effect. Wise et al. ${ }^{202}$ originally concluded that ' . . a history of testing with normal reward and pimozide was equivalent to drug-free testing without reward'. This precipitated a number of papers that produced evidence that responding under pimozide plus normal reward was not equivalent to extinction; thus, it was shown that pimozide produced an overall decrease in food maintained responding independent of extinction-like effects $8,53,54,72,96,124,141,190$. As was discussed earlier there is abundant evidence that DA plays a role in locomotor activity. The above effects are consistent with this but a number of these and other studies, as discussed at the beginning of this section, reporting a cumulative decrease in responding over days of testing with pimozide suggest that DA also is involved in food reinforcement-produced incentive learning.

One set of studies that may be relevant to this section is those concerned with the effects of various psychomotor stimulants on the acquisition of responding with conditioned reinforcement. These studies involved first exposing undrugged animals to 
pairings of a neutral stimulus with a primary incentive stimulus; then the acquisition of an operant response that produced the conditioned stimulus, no longer followed by food, in animals treated with various DA agonists was observed. Results revealed that animals treated with the stimulant, pipradrol showed an enhanced level of responding on a lever that produced conditioned reinforcement $12,13,83,153-155,157,158$. Although two earlier reports found no significant effect of amphetamine with this procedure ${ }^{13,155}$, a more extensive recent study has shown that this drug produces effects similar to those seen with pipradrol158. Enhancement of responding for conditioned reinforcement also has been observed in animals treated with a phenyltropane analogue of cocaine (WIN 35,428 ) but not with another analogue (WIN 35,065-2), cocaine itself or with apomorphine ${ }^{13,158}$.

The possibility that the effects of pipradrol and amphetamine in these studies were mediated by DA gains some support from the observation that their stimulant effect on lever pressing can be antagonized by intrastriatal and intraaccumbens 6-OHDA ${ }^{156}$. It was found that when animals were required to perform a chain of two responses to receive a conditioned reinforcer, treatment with pipradrol resulted in a large increase in the rate of the second response only, actually resulting in a reduction in the number of conditioned reinforcers received ${ }^{154}$. This result might suggest that in these studies prior conditioning influenced response selection whereas the DA agonists, pipradrol, D-amphetamine and WIN 35,428 simply produced repetition or stereotypy of that response ${ }^{158}$. From this point of view, these results may not be directly related to DA's role in incentive learning but rather may reflect DA's locomotor function.

One difficulty with this interpretation is the negative results observed with cocaine, WIN 35,065-2, and especially the direct acting DA agonist, apomorphine. The lack of effect with apomorphine may be attributable to the fact that this drug's stimulatory action is relatively independent of ongoing DA activity, possibly reducing the response selection effects of prior conditioning; a similar hypothesis has been used to explain the failure of apomorphine to increase rates of intracranial self-stimulation ${ }^{158}$. Pipradrol and D-amphetamine, drugs that do enhance responding for conditioned reinforcement also en- hance neurogenic DA release and block re-uptake ${ }^{158}$, at least raising the possibility that their influence is somewhat greater at DA synapses that are already active. Similarly, WIN 35,428, WIN 35,065-2 and cocaine block re-uptake of catecholamines with their relative potency being directly related to their enhancing effects on responding for conditioned reinforcement ${ }^{158}$. Thus, it seems possible that the effects of various psychomotor stimulants on the acquisition of responding with conditioned reinforcement may be related to their ability to enhance, somewhat selectively, transmission at DA synapses that are already active. As this effect is seen following the establishment of incentive conditioning, it is possible that it is related primarily to DA's locomotor function.

A large number of studies have employed brain stimulation reinforcement (BSR) in testing a possible role for DA in incentive learning60,198-200. There is now good evidence that the effects of BSR on behavior are similar to those of food; for example, conditioned animals initiate responding for BSR without priming and can be trained to lever press for BSR on lean schedules of reinforcement, BSR can be used to establish neutral stimuli as conditioned reinforcers and extinction following the discontinuation of BSR is gradual $^{9,14,128,193}$. Furthermore, the effects of pimozide on BSR- and food-maintained operant responding are comparable. Thus, pimozide seems to produce an extinction-like decrease in BSR-reinforced responding 64,65 . Several researchers have employed sophisticated testing procedures to distinguish between possible motor impairments versus reinforcement-related incentive conditioning impairments produced by disruptions of DA neurotransmission. Rats were implanted with a unilateral stimulating electrode into the ascending DA fibers and then the effects of ipsilateral versus contralateral DA denervation or receptor blockade on BSR were compared. These studies found that the ipsilateral lesion eliminated the behavior whereas the contralateral lesion produced only transient effects showing that intact DA neurons were required to maintain responding; the possibility of a motor deficit appeared to be ruled out because the similar contralateral lesion did not eliminate the behavior ${ }^{102,129.139}$. Recently, one of these studies 102 has been criticized on the basis of differential severity of DA depletion on the ipsilateral 
versus contralateral side and data were reported showing bilateral self stimulation deficits following more complete unilateral DA depletions ${ }^{28}$. Although these results support a motor impairment interpretation of the effects of DA denervation on BSR, other studies ${ }^{129,139}$ are not subject to the same criticism and continue to support the hypothesis that the effectiveness of incentive stimuli at maintaining operant responses may require intact DA systems. Using different procedures, others have come to the same conclusion ${ }^{208}$.

The hypothesis that DA neurons mediate the effects of reinforcement on behavior attains further support from the finding that animals will perform operant responses that result in intravenous injections of DA agonists and that this behavior undergoes extinction if DA transmission is disrupted. An interesting feature of this procedure is that self-administration rates transiently increase under the influence of neuroleptics, making motor impairments unlikely candidates for producing the effect. Thus, D-amphetamine and cocaine self-administration rates are transiently increased and then decrease following pimozide or DA-depleting 6-OHDA lesions $^{49,159,206,207}$.

As discussed in the previous section, numerous studies have shown that animals with a history of being injected with a stimulant such as D-amphetamine or cocaine are more active than controls when injected with saline and placed in the environment previously associated with the drug11,84,89,142,147,160,188. Recently, the importance of DA in this placebo effect was confirmed when it was shown that pimozide blocked the establishment of conditioning 11 . In that study it also was shown that the same dose of pimozide that blocked establishment of conditioning failed to antagonize the expression of the effect in animals previously conditioned with $\mathrm{D}$-amphetamine but without pimozide. This result provides further support for the hypothesis that previously conditioned animals can continue to respond for a time when DA function is blocked.

Some researchers have employed two distinct stimulus situations during conditioning to test the hypothesis that previously trained animals can continue to respond for a time when DA function has been blocked. In two different studies, animals previously trained to respond for BSR showed an extinction-like decrease in responding when tested in the presence of one set of reinforcement-signaling stimuli while under the influence of pimozide; this finding is consistent with numerous studies discussed above. However, when they were presented with the other set of reinforcement-signaling stimuli, these drugged, apparently extinguished animals were observed to begin again to respond; responding was transient, again showing an extinction-like decline ${ }^{10,67}$. The results of these studies demonstrate that previously trained animals observed to cease to respond while under the influence of DA receptor blocking drugs can, in fact, respond. The results indicate that established incentive stimuli can elicit responses for a time in DA disrupted animals. In the continued absence of normal DA neurotransmission, the effects of previous incentive learning are lost leading to a loss of responding. Note, however, that the blockade of DA receptors alone is not sufficient to produce a loss of incentive conditioning; rather it is the combination of DA receptor blockade and exposure to previously established incentive stimuli that leads to this loss.

Finally, the effect of disruption of DA neurotransmission on established avoidance responding is consistent with the preceding analysis. Numerous studies have shown that manipulations that disrupt DA systems cause an extinction-like decrease in well-trained avoidance responding7,110,134. Some authors have reported that prior straining resulted in a significant decrease in the disruptive effects of haloperidol or 6-OHDA lesions on avoidance responding ${ }^{62,209}$; however, with more extensive testing even these initially less impaired rats show a loss of avoidance responses $7,21.110,134$. These findings support the hypothesis that intact DA neurons may be needed not only for the acquisition of incentive learning but also for the continued effectiveness of conditioned incentive stimuli.

\section{SUMMARY}

Brain DA systems appear to be significantly involved in locomotor activity and in the acquisition and maintenance of conditioned incentive motivation; they appear to play no significant role in stimulus-stimulus associative learning.

In looking at the relationship between DA activity and locomotion, research has shown that as transmis- 
sion in DA neurons rises, for example, under the influence of stimulant drugs, locomotor activity rises or begins to give way to stereotyped activity that may be confined to a restricted area; conversely, when transmission at DA synapses is suppressed by DA receptor blocking drugs or neurotoxic lesions of DA neurons, locomotor activity declines. Placing the emphasis on reactivity to unconditioned sensory stimuli rather than motor activity, it has been found that increased activity in DA neurons leads to increased responsiveness to stimuli; decreased DA activity, on the other hand, results in apparent sensory neglect. Thus, the level of tonic activity in DA neurons appears to be directly related to the level of locomotor activity or responsiveness to unconditioned stimuli.

DA neurons also seem to play an important role in incentive motivational learning. Thus, when reinforcement occurs, increased activity in DA neurons ${ }^{78-80,98,127,131}$ may result in incentive conditioning of stimuli associated with the reinforcement event. As a consequence of this learning, these stimuli have an enhanced ability to activate operant response systems. If DA receptors are blocked during acquisition training, incentive learning appears to fail to occur although s-s associations may be learned. If DA activity is stimulated by drugs such as amphetamine or cocaine, incentive learning will occur, stimuli in the test environment acquiring the ability to elicit responses. If DA systems are blocked in previouslyconditioned animals, the conditioned incentive motivational properties of reinforcement-related stimuli are slowly lost with use until responding is reduced to a low level. This latter observation might indicate that during incentive conditioning DA neurons mediate a change in synaptic effectiveness that thereafter can influence response systems for a time even when DA functioning is greatly impaired.

\section{THEORETICAL IMPLICATIONS}

\subsection{Introduction}

It is now well established that the brain's DA systems play a central role in the pathogenesis of Parkinson's disease and this finding has led to the successful treatment of the disease with the DA precursor, L-DOPA ${ }^{85,163}$. Considerable evidence also implicates brain DA in schizophrenic disorders but the specific role of the various DA systems remains uncertain $108,120,177,196$. Although DA is implicated in these disorders, little is known about the actual role of DA neurons in the functioning of the brain. Furthermore, it is not known how changes in DA activity produce severe alterations in behavior. However, a consideration of the anatomical organization of DA systems in conjunction with the results of studies of the behavior of animals with altered DA activity reveals some insights that provide the basis for integrating apparently diverse laboratory and clinical observations. The following paragraphs present a possible mechanism for DA-mediated learning; then the anatomy of DA systems will be discussed briefly. This will be followed by a consideration of the relationship between this anatomy and the mechanism of incentive learning. Finally, brief comments on the relevance of this information to clinical observations of Parkinsonian and psychotic individuals will be presented.

\subsection{A possible mechanism}

A mechanism for DA-mediated learning of a longterm nature has been described by researchers employing the sucrose gap in vitro recording technique ${ }^{112,113}$. These studies looked at the responses of the efferent cells of the rabbit superior cervical ganglion to various pharmacological agents. This ganglion contains cholinergic afferents and DA interneurons that both synapse on the efferent cells. It was found that a bricf superfusion of the ganglion with DA resulted in a long-lasting enhancement of the cholinergic response; employing conventional electrophysiological recording techniques, researchers recently have replicated these results 5 . This type of effect has been termed heterosynaptic facilitation ${ }^{95}$. Additionally, data revealed that this DA-produced change was mediated intracellularly by the activation of a DA-receptor-linked adenylate cyclase that stimulated the formation of cyclic adenosine monophosphate (AMP) from adenosine triphospate. Although the exact mechanism remains unknown, it is possible that the DA-stimulated cyclic AMP enhances the response of the cell to acetylcholine by altering the ‘. . synthesis of certain proteins having specific functional roles in synaptic physiology. This might constitute one component of the mechanism by 
which long-term information storage (i.e. learning) and retrieval (i.e. memory) can occur'73.

Although the demonstration of a cyclic AMP-mediated DA-produced heterosynaptic change in responsiveness to acetylcholine involved the peripheral nervous system (PNS), recent data indicate that some CNS DA receptors also are coupled to adenylate cyclase and that activation of these receptors by DA stimulates the formation of cyclic AMP23,73, 137,166. This DA-stimulated cyclic AMP may play a similar role in producing long term changes in the CNS as those described in the PNS ${ }^{165}$. Since DA may be involved in incentive learning, it is further possible that this type of learning may be mediated by the adenylate cyclase-coupled DA receptor. It is perhaps worth noting that there are at least two types of central DA receptors, termed D-1 and D-2, denoting the DA receptor that is linked to DA-sensitive adenylate cyclase and the DA receptor that is not adenylate cyclase-linked, respectively ${ }^{97}$. This classification scheme has been elaborated recently ${ }^{35,170,179}$.

\subsection{Anatomy of the basal ganglia}

The hypothesis that DA-mediated incentive learning might be produced by a central heterosynaptic mechanism similar to that described in the PNS is further supported by the anatomy of the dopamine terminal regions. One of the striking aspects of the nigrostriatal and mesolimbic DA systems is that they can be considered to terminate at stimulus-response interfaces in the brain. Thus, the nigrostriatal system projects to the neostriatum, an area that receives massive input from all major sensory areas of the neocortex $77,100,195$ and sends its efferents to important motor nuclci, the globus pallidus and zona reticulata of the substantia nigra ${ }^{30,88,130}$. Similarly, the mesolimbic DA neurons project to the ventral striatum, viz., the nucleus accumbens and olfactory tubercle; these areas receive sensory input from allocortical structures including the entorhinal and pyriform cortex (olfactory) and the hippocampus ${ }^{82,105}$. In turn, they project to the ventral pallidum (that includes part of the substantia innominata), an area that may serve a motor function 81,82 and to the substantia nigra, an important motor area ${ }^{133}$. The DA projection to the frontal cortex is more difficult to characterize; although the frontal cortex is extensively intercon- nected with other cortical regions that are sensory in nature and projects to the neostriatum and brainstem areas that could be viewed as motor, the function of this area and of its DA afferents from VTA is still poorly understood 69,116 . However, the similarities in the organization of the terminal regions of the nigrostriatal and mesolimbic systems are striking and have been emphasized by several authors $76,81,82,132$. Further, it should be noted that there is a relatively small number of DA cell bodies in their nuclei of origin and that these cells arborize extensively, forming many en passant synapses in their terminal regions; human DA cells may form as many as 500,000 synaptic contacts $^{125}$. This suggests that the DA systems act en masse rather than serving a specific information processing function.

Anatomical studies have revealed that there are cholinergic neurons within the striatum, nucleus accumbens and olfactory tubercle and that they are most likely interneurons ${ }^{58,101}$. Additionally, it has been found that these striatal cholinergic interneurons are influenced by cortical afferents ${ }^{175}$. Hassler ${ }^{76}$ reviewed a large number of ultrastructural studies and concluded that striatal interneurons and DA afferents synapse on common cells, possibly striatal efferents. These interneurons may be cholinergic and the receptors they affect are muscarinic ${ }^{204}$. Finally DA stimulated adenylate cyclase is found in the DA

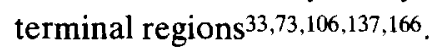

From the above considerations it is possible to see that all the elements of the peripheral heterosynaptic mechanism demonstrating a role for DA in learning may be found in the CNS. Specifically, these elements include cells receiving both DA and muscarinic cholinergic afferents and having the enzyme, adenylate cyclase linked to DA receptors. Furthermore, a variety of neurochemical interactions between acctylcholine and DA within the striatum have been described ${ }^{185}$. A recent study, using $\left[{ }^{3} \mathrm{H}\right](-)$ 3-quinuclidinyl benzilate to identify striatal muscarinic receptors reported that the DA agonist, apomorphine enhanced binding by converting low to high affinity receptors. Further pharmacological characterization of this effect revealed that it was antagonized by anti-DA drugs known to block D-1 receptors (e.g. cis-flupenthixol) but not by specific D-2 receptor blockers (e.g. sulpiride) 52 . Although DA was found to enhance the effectiveness of muscarinic 
cholinergic receptors via the activation of a DA receptor-linked adenylate cyclase in the PNS as described in Section 5.2, the exact mechanism was not known. These new findings using CNS tissue suggest the possibility that DA changes the effectiveness of cholinergic synapses by converting low to high affinity receptors.

\subsection{Possible synaptic events underlying the establish- ment of incentive learning}

If DA mediates incentive learning in the CNS, the normal sequence of events might be as follows. As an animal moves through its environment, the stimuli impinging on its senses constantly change and, therefore, the pattern of activity in sensory neurons keeps changing. Since neurons from all sensory areas of the neocortex and allocortex project into the (dorsal and ventral) striatum $77,82,100,105,195$ where they influence cholinergic interneurons ${ }^{175}$, the subset of activated interneurons also keeps changing; their particular muscarinic synapses are active accordingly. When a primary incentive stimulus is encountered, the DA system may be activated en masse resulting in a heterosynaptic change, viz., an increase in the number of high affinity receptors at those muscarinic synapses that were most recently active (see below). As a result, in the future only those stimuli that activate the cholinergic interneurons with modified synapses will be conditioned incentive stimuli; i.e., they will have enhanced ability to activate operant response systems represented by striatal efferents.

For this model to work it is necessary that DA-mediated changes in cholinergic receptors occur only at the subset of cholinergic synapses that was most recently active. A possible mechanism for this time coupling has been demonstrated in the isolated rat retina ${ }^{26}$. It was shown that the cholinergic agonist, carbachol potentiated DA-stimulated cyclic AMP formation. If a similar mechanism operated in the striatum, then when the DA systems were discharged (by a primary incentive stimulus), the most recently active cholinergic synapses would be most strongly altered because they would have enhanced the amount of DA-stimulated cyclic AMP by potentiating the coupling of adenylate cyclase to nearby DA receptors on the same cell26; therefore, the most recently encountered stimuli will become the strongest incentive stimuli (see Fig. 1). Although adequate data are not yet available, it is possible that guanyl nucleotides participate in the cholinergic influence on coupling of adenylate cyclase to DA receptors. Thus, muscarinic receptors are known to influence the synthesis of guanyl nucleotides ${ }^{73}$. Furthermore, endogenous guanyl nucleotides have been shown to mediate the coupling of adenylate cyclase to DA receptors $^{32}$.

The results of some recent electrophysiological studies provide further evidence for a modulatory role for DA in the brain. The responses of nucleus accumbens cells to stimulation of the amygdala or VTA were recorded. Note that as the amygdala receives extensive sensory input ${ }^{136}$ the amygdala-accumbens projection may be viewed as sensory in nature. It was observed that the accumbens cells' response to amygdalar stimulation was decreased if it was immediately preceded by VTA stimulation. Furthermore, it was shown that these modulatory effects of VTA stimulation were mediated by DA. The authors concluded that DA may play an important role in mediating the extent to which (sensory) limbic structures can exert an influence on motor output via the nucleus accumbens ${ }^{205}$. Although these results showed that DA produced a decrease in responsiveness whereas the present model might predict an increase, it is possible for example that the recorded cells were postsynaptic to those cells modified by DA. Nevertheless, the observations are relevant in the present context and are consistent with the proposal that DA modulates the influence that various sensory events have on motor output.

It is interesting to note that Deutsch and his colleagues ${ }^{51}$, based on extensive psychopharmacological research, have concluded that central muscarinic cholinergic synapses are modified as a result of learning and that the modification involves increased cho" linergic sensitivity of the postsynaptic membrane. It is tempting to speculate that the time course of learning and forgetting that they ascribe to these synapses is the time course of the possible DA-produced change underlying incentive conditioning. It is beyond the scope of this paper to review the literature implicating acetylcholine in behavior and learning. The interested reader should consult the excellent reviews already available (see ref. 22 ).

Perhaps it is worth mentioning at this point that the 


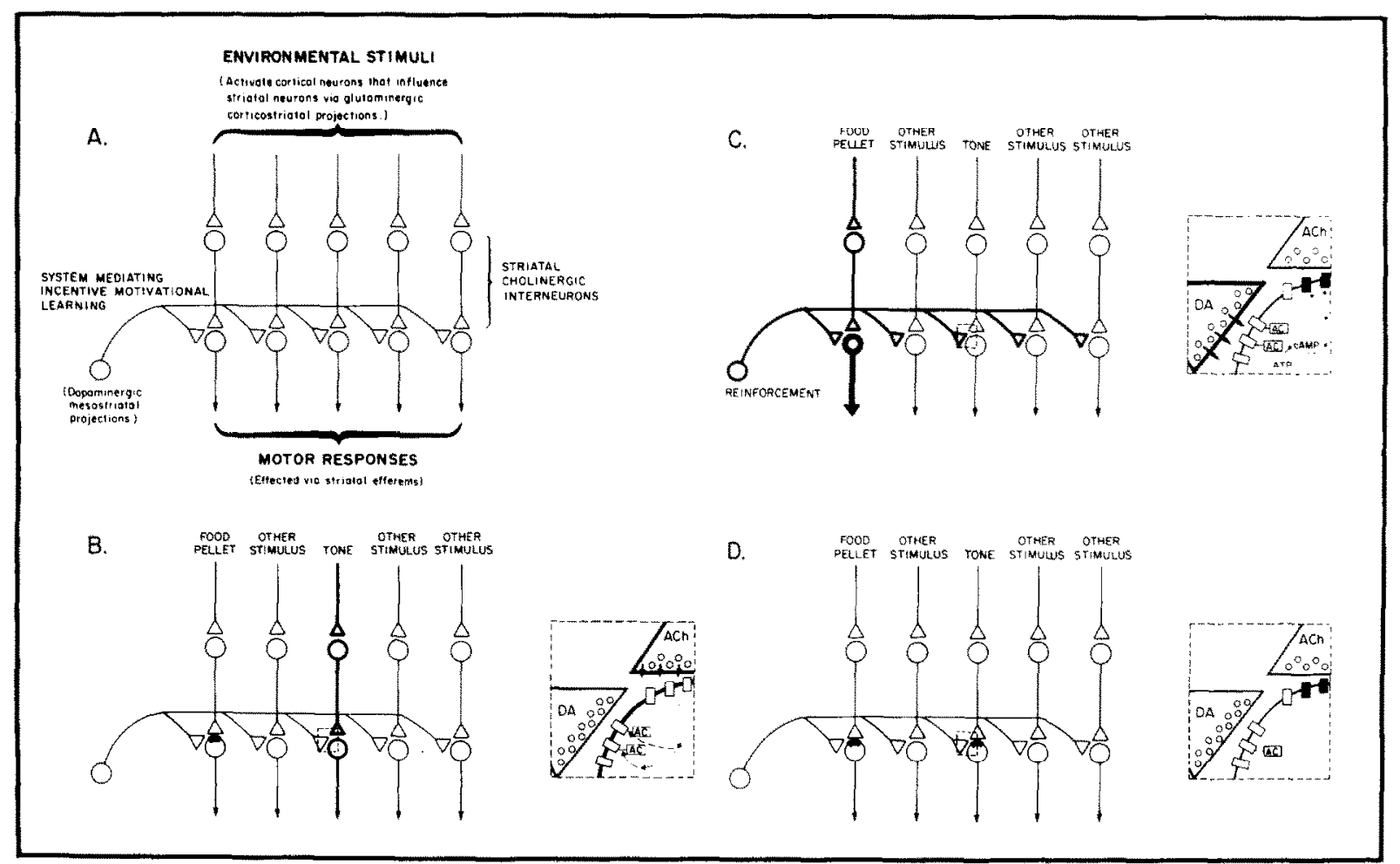

Fig. 1. A: intrastriatal connections that may be involved in incentive motivational learning. Here the term 'striatum' refers to both the dorsal and ventral striatum as discussed in Section 5.3 of the text. As depicted, each individual ncuron presumably represents a set of neurons in the brain. B: possible mechanism through which environmental stimuli may influence the coupling of adenylate cyclase to dopaminergic (D-1) receptors. Thus, when a tone is present in the environment, stimulation of sensory pathways may lead to activation of a set of cortical neurons that may influence a set of striatal cholinergic interneurons, as indicated by the heavy lines. The square to the right represents an enlargement of the connections inside the broken square on the diagram to the left; through an as yet unknown process, stimulation of muscarinic receptors by acetylcholine $(\mathrm{ACh})$ may enhance the coupling of adenylate cyclase (AC) to DA receptors, as shown by the broken lines and arrows (see Section 5.4 in the text). C: possible mechanism through which DA-stimulated adenylate cyclase may alter the strength of cholinergic synapses. Presentation and ingestion of a food pellet results in stimulation of sensory neurons possibly leading to activation of cortical cells that influence striatal interneurons (heavy lines leading from food pellet') and in 'reinforcement' involving activation of DA neurons. Since the tone was the most recent environmental event preceding food, presumably DA receptors common to the cells activated by the tone have enhanced coupling to $\mathrm{AC}$ (see $\mathrm{B}$ ). In the square to the right in $\mathrm{C}$, the action of DA at these receptors leads to the formation of cyclic adenosine monophosphate (cAMP) from adenosine triphosphate (ATP) which may lead to an enhancement of the affinity of nearby cholinergic receptors (see Section 5.3 in the text), depicted by filled rectangles. D: the tone has become a conditioned incentive motivational stimulus, having enhanced ability to influence striatal efferents. This change is represented in the diagram to the left by the membrane thickening shown on striatal efferents activated by the tone. The possible structural basis, shown to the right, is an increased number of high affinity cholinergic receptors (filled rectangles). Note that prior conditioning would have similarly enhanced the incentive properties of stimuli produced by the food pellet itself, as also shown in B, C and D.

same DA neurons may mediate both the locomotor and learning functions ascribed to them in this review. Thus, when no primary incentive stimuli are present, the tonic level of activity in DA cells may mediate the level of locomotor activity in the animal, or, from the sensory point of view, the level of responsiveness to unconditioned stimuli. The observation that brain DA activity shows a circadian rhythmicity, being highest during wakefulness in rats ${ }^{68}$ and monkeys 138 is consistent with this view. Presumably, little incentive learning is occurring as a result of this tonic DA activity. When a primary incentive stimulus is encountered, activity in these same DA neurons may be increased and under the influence of the resultant higher concentrations of DA, incentive learning may occur. According to the model developed here, the strongest learning would be produced by those DA synapses that most effectively stimulate the formation of cyclic AMP. This would occur at precisely those synapses where the coupling of D-1 
receptors to adenylate cyclase had been enhanced, i.e., those synapses most recently activated by environmental stimuli. Thus, those stimuli become conditioned incentive stimuli. As DA also influences locomotor activity, enhanced DA release resulting from the presentation of a primary incentive stimulus, besides producing incentive learning, should also cause a transient elevation in general locomotion. It is gratifying to note that the unconditioned activating effects of primary incentive stimuli are well documented 24.119 .

\subsection{Possible synaptic events underlying extinction}

As has been discussed above, intact DA systems appear to be required both for the establishment and maintenance of incentive learning. However, once incentive learning is established it, for a time, can maintain responding even when DA function is disrupted; in the continued absence of normal DA functioning, as in the extinction situation, exposure to conditioned incentive stimuli results in a loss of their ability to elicit responses until eventually the learned behavior no longer occurs.

The temporary independence of established incentive learning from DA can be understood with reference to the model presented in the previous paragraphs. Thus, the structural basis of incentive learning may be modified muscarinic synapses. Specifically, DA may mediate a heterosynaptic change by activating a receptor-linked adenylate cyclase; this may lead to an increase in the number of high affinity muscarinic receptors on the postsynaptic side of the striatal cholinergic interneurons most recently activated by environmental stimuli. Possibly, when DA receptors subsequently are blocked, or when the primary incentive stimulus no longer is presented, conditioned incentive stimuli can maintain responding via these modified muscarinic synapses for a time but with continued use they lose their effectiveness. What structural changes might underlie this eventual loss of effectiveness of conditioned incentive stimuli?

Unfortunately, to my knowledge data directly relevant to the answer to this question are not yet available. One possibility is that the proposed DA-mediated heterosynaptic change leading to an increase in the number of high affinity muscarinic receptors is reversed when those receptors are used repeatedly in the absence of augmented DA neurotransmission produced by reinforcement. Although the intracellular mechanisms that mediate DA-produced changes in affinity of muscarinic receptors remain to be worked out in detail, it has often been suggested that the metabolic consequences of DA-stimulated adenylate cyclase include protein phosphorylation through activation of protein kinases ${ }^{73}$. If the phosphorylated proteins were themselves the muscarinic receptors, it is possible that this reaction is responsible for the affinity change. If the binding of acetylcholine to the muscarinic receptor resulted in dephosphorylation, this could provide a mechanism underlying the gradual loss of incentive conditioning through repeated use when DA function is blocked. Some recent studies showing that a myofibrillar protein becomes phosphorylated in response to $\beta$-adrenergic agonists and dephosphorylated in response to muscarinic agonists ${ }^{75}$ provide indirect support for the proposed mechanism.

\section{CLINICAL IMPLICATIONS}

Schizophrenia is a debilitating human disease. It is characterized by a period of active psychotic symptomatology including delusions, hallucinations, or certain disorders of thought and having a duration, with residual phases, of at least 6 months ${ }^{182}$. There are several lines of evidence that suggest that hyperfunctioning of DA underlies this disease. These include the original observations that gave rise to the DA hypothesis of schizophrenia; viz., DA agonists such as D-amphetamine and cocaine are psychotogenic and DA receptor blockers such as chlorpromazine are successful in the treatment of the disease ${ }^{176-178}$. Additionally, recent studies of post-mortem brain tissue from schizophrenic patients provide support for the DA hypothesis. Thus, receptor binding studies have shown that there is an abnormally high level of DA receptors associated with the disease $^{44,108,170,178 \text {. }}$

It should be noted that the results from several of the binding studies suggest that there is an overabundance of D-2 receptors in the schizophrenic brain. Furthermore, the average clinical dose of DA receptor blocking drugs used in the treatment of schizophrenia is highly correlated with their ability to inhibit by $50 \%$ the specific binding of $\left[{ }^{3} \mathrm{H}\right]$ haloperidol $\left(\mathrm{IC}_{50}\right)$ 
to homogenerates of caudate nucleus ${ }^{170} ;\left[{ }^{3} \mathrm{H}\right]$ haloperidol is thought to label D-2 receptors. Additionally, the correlation of average clinical dose of neuroleptics with ability to inhibit DA-stimulated adenylate cyclase (D-1 receptors) is poor 170 . Taken together, these data suggest that the $D-1$ receptor may play no important role in the development of schizophrenia ${ }^{178 .}$

On the other hand, a role for D-1 receptors cannot yet be ruled out. Thus, DA receptor blockers that are highly specific for D-1 receptors, e.g. cis-flupenthix$\mathrm{ol}^{87}$, are reported to be effective in the treatment of schizophrenia ${ }^{45}$. Furthermore, although the correlation between average clinical dose of neuroleptics and $\mathrm{IC}_{50}$ values on $\mathrm{D}-2$ receptors is high, there is usually a delay of a number of days between the onset of neuroleptic therapy and improvement in the disease condition 117 . From these observations it seems possible that D-1 receptors may be involved in schizophrenia and that blocking of D-2 receptors may not be necessary to successfully treat the disease. However, the resolution of this question of the role of D-1 and D-2 receptors in schizophrenia awaits further research. Nevertheless, if overactivity at DA synapses does take place in the brains of individuals suffering from schizophrenia, some of the classical symptoms may be understood with reference to inappropriate incentive learning.

Based on the results of a wide range of psychological studies, many authors have concluded that schizophrenics suffer from an inability to ignore irrelevant stimuli93.126,152. As outlined in Section 3.3, DA seems to play a key role in incentive learning, i.e., the acquisition by neutral stimuli of an enhanced ability to elicit operant responses. If there was an overstimulation of DA receptors in the brains of schizophrenics, DA-mediated incentive learning might alter indiscriminantly the ability of stimuli to influence response systems. A consequence of this inappropriate incentive learning might be that the affected individual would lose his or her ability to ignore irrelevant stimuli.

It should be noted that stimulus-stimulus associative learning appears to be independent of DA function; if this type of learning remains intact in schizophrenics, it is possible that the paranoia or delusions of grandure, often observed in these individuals, are elaborate cognitive interpretations of the apparent meaningfulness of stimuli that normally should be irrelevant. The Parkinsonian would represent the other side of the coin; for this individual, incentive learning might fail to occur. In spite of intact abilities to recognize and associate stimuli, the untreated Parkinson's patient may be impaired in his or her ability to access response systems except, perhaps, under conditions of danger ${ }^{168,169}$.

One of the main features of the model developed here is that, once established, DA-mediated incentive learning can influence behavior for a time even after DA neurotransmission has been blocked. This may explain one of the most perplexing problems with the theory that schizophrenia results from DA hyperfunctioning; that is that neuroleptics, although immediately affecting DA receptors, do not produce therapeutic effects for a number of days after the initiation of treatment ${ }^{117}$. Just as previously established conditioned incentive stimuli can for a time maintain responding in animals with disrupted DA function, perhaps aberrant incentive learning in schizophrenics can continue to influence behaviour for a time; possibly in both cases, conditioned incentive stimuli lose their effectiveness when repeatedly used in the absence of excessive DA activity. A further consideration of potential clinical relevance is that, until used in the absence of reinforcement, conditioned incentive stimuli retain their response eliciting ability. As discussed in Section 3.3.3, this has been shown in experiments reporting that a conditioned incentive stimulus could reinstate responding in neuroleptictreated rats that had ceased to respond ${ }^{10,67}$. With reference to the treatment of a schizophrenic, this might suggest the following. In the individuals home and work environment, aberrant incentive learning may be occurring because of DA hyperfunctioning and symptoms of schizophrenia ensue. The individual is then hospitalized, treated with neuroleptics and the symptoms subside. However, when returned to the home and/or work environment, even with continued medication the symptoms would reappear at least transiently, because of previous incentive learning. These considerations would suggest that the most effective treatment strategy would be to administer neuroleptics in the environments originally associated with the development of the disease. 


\section{SUMMARY}

The discovery that the brain contains neurons utilizing dopamine (DA) as their transmitter has led to studies of the behavioral function of these neurons. Changes in overall level of activity of DA neurons appear to produce parallel changes in locomotor activity. Additionally, DA neurons seem to mediate in part the effects of biologically significant (reinforcing) stimuli on learning. One way in which reinforcing stimuli produce learning is to increase the incentive motivational (response-eliciting) properties of neutral stimuli associated with them; also, reinforcing stimuli maintain the incentive motivational properties of previously conditioned incentive stimuli. Normal DA functioning appears to be required for the establishment and maintenance of incentive learning in naive animals. Previous incentive learning in trained animals can influence behavior for a time even when the function of DA neurons is dis-

\section{REFERENCES}

1 Ahlenius, S., Engel, J. and Zoller, M., Effects of apomorphine and haloperidol on exploratory behavior and latent learning in mice, Physiol. Psychol, 5 (1977) 290-294.

2 Anden, N. E., Butcher, S. G., Corrodi, H., Fuxe, K. and Ungerstedt, U., Receptor activity and turnover of dopamine and noradrenaline after neuroleptics, Europ. I. Pharmacol., 11 (1970) 303-314.

3 Anisman, H., Neurochemical changes elicited by stress In H. Anisman and G. Bignami (Eds.), Psychopharmacology of Aversively Motivated Behavior, Plenum Press, New York, 1978, pp. 119-172.

4 Arnt, J., Hyperactivity following injection of a glutamate agonist and 6,7-ADTN into rat nucleus accumbens and its inhibition by THIP, Life Sci., 28 (1981) 1597-1603.

5 Ashe, J. H. and Libet, B., Modulation of slow postsynaptic potentials by dopamine, in rabbit sympathetic ganglion, Brain Res., 217 (1981) 93-106.

6 Bartus, R. T., Short-term memory in the rhesus monkey: effects of dopamine blockade via acute haloperidol administration, Pharmacol. Biochem. Behav., 9 (1978) 353-357.

7 Beer, B. and Lenard, L. G., Differential effects of intraventricular administration of 6-hydroxydopamine on behavior of rats in approach and avoidance procedures: reversal of avoidance decrements by diazepam, Pharmacol. Biochem. Behav., 3 (1975) 879-886.

8 Beninger, R. J., A comparison of the effects of pimozide and nonrcinforcement on discriminated operant responding in rats, Pharmacol. Biochem. Behav., 16 (1982) $667-669$.

9 Beninger, R. J., Bellisle, F, and Milner, P. M., Schedule control of behavior reinforced by electrical stimulation of the brain, Science, 196 (1977) 547-549. rupted; however, with continued testing in the absence of normal DA functioning, previously established conditioned incentive stimuli cease to influence behavior. From these observations and recent physiological, anatomical and biochemical studies of DA systems it is suggested that the biological substrate of DA-mediated incentive learning is a heterosynaptic facilitation of muscarinic cholinergic synapses. This model has important clinical implications since it has been suggested that DA hyperfunctioning underlies the development of schizophrenia.

\section{ACKNOWLEDGEMENTS}

I wish to thank Drs. Hymie Anisman of Carleton University and R.G. Weisman of Queen's University for their valuable assistance in the preparation of this manuscript. Supported by grants from the Medical Research Council and the Ontario Ministry of Health.

10 Beninger, R. J, and Freedman, N. L., The use of two operants to examine the nature of pimozide-induced decreases in responding for brain stimulation, Physiol. Psychol, $10(1982)$ 409-412.

11 Beninger, R. J, and Hahn, B. L., Pimozide blocks establishment but not expression of amphetamine-produced environment-specific conditioning, Science, 220 (1983) 13041306

12 Beninger, R. J., Hanson, D. R. and Phillips, A. G., The effects of pipradrol on the acquisition of responding with conditioned reinforcement: a role for sensory preconditioning, Psychopharmacology, 69 (1980) 235-242.

13 Beninger, R. J., Hanson, D. R. and Phillips, A. G., The acquisition of responding with conditioned reinforcement effects of cocaine, (+)-amphetamine and pipradrol, Brit. J. Pharmacol., 74 (1981) 149-154.

14 Beninger, R. J., Laferriere, A. and Milner, P. M., An investigation of responding on schedules of electrical brain stimulation reinforcement, Canad. J. Phychol./Rev. Canad. Psychol., 32 (1978) 106-115.

15 Beninger, R. J., MacLennan, A. J. and Pinel, J. P. J., The use of conditioned defensive burying to test the effects of pimozide on associative learning, Pharmacol. Biochem. Behav., 12 (1980) 445-448.

16 Beninger, R. J., Mason, S. T., Phillips, A. G., and Fibiger, H. C. The use of conditioned suppression to evaluate the nature of neuroleptic-induced avoidance deficits, $J$. Pharmacol. exp. Ther, 213 (1980) 623-627.

17 Beninger, R. J., Mason, S. T., Phillips, A. G. and Fibiger, $H$. C., The use of extinction to investigate the nature of neuroleptic-induced avoidance deficits, Psychopharmacology, $69(1980) 11-18$

18 Beninger, R. J. and Phillips, A. G., The effect of pimozide on the establishment of conditioned reinforcement, $P s y$ chopharmacology, 68 (1980) 147-153. 
19 Beninger, R. J. and Phillips, A. G., The effects of pimozide during pairing on the transfer of classical conditioning to an operant discrimination, Pharmacol. Biochem. Behav., 14 (1981) 101-105.

20 Beninger, R. J. and Phillips, A. G., The effects of food deprivation on pimozide-induced decreases in DRL responding, Neurosci. Lett. Suppl. 7 (1981) 375.

21 Beninger, R. J., Phillips, A. G., and Fibiger, H. C., Prior training and intermittent retraining attentuate pimozideinduced avoidance deficits, Pharmacol. Biochem. Behav., 18 (1983) 619-624.

22 Bignami, G. and Michalek, H., Cholinergic mechanisms and aversively motivated behaviors. In $\mathrm{H}$. Anisman and G. Bignami (Eds.), Psychopharmacology of Aversively Motivated Behavior, Plenum Press, New York, 1978, pp. 173-256

23 Bindra, D., How adaptive behavior is produced: a perceptual-motivational alternative to response-reinforcement, Behav. Brain Sci., 1 (1978) 41-91.

24 Bindra, D. and Campbell, J. F., Motivational effects of rewarding intracranial stimulation, Nature (Lond.), 215 (1967) 375-376.

25 Bolles, R. C., Reinforcement, expectancy, and learning, Psychol. Rev., 79 (1972) 394-409.

26 Brown, J. H. and Rietow, M., Muscarinic-dopaminergic synergism on retinal cyclic AMP formation, Brain Res., 215 (1981) 388-392.

27 Brozoski, T. J., Brown, R. M., Rosvold, H. E. and Goldman, P. S., Cognitive deficit caused by regional depletion of dopamine in prefrontal cortex of rhesus monkey, Science, 205 (1979) 929-932.

28 Carey, R. J., Unilateral 6-hydroxydopamine lesions of dopamine neurons produce bilateral self-stimulation deficits, Behav. Brain Research, 6 (1982) 101-104.

29 Carlsson, A., Lindquist, M., Magnusson, T. and Waldeck, B., On the presence of 3-hydroxytyramine in brain, Science, 127 (1958) 471.

30 Carpenter, M. B., Human Neuroanatomy, Williams and Wilkins, Baltimore, MD, 1976, pp. 496-520.

31 Carter, D. J. and Pycock, C. J., Behavioural and biochemical effects of dopamine and noradrenaline depletion within the medial prefrontal cortex of the rat, Brain Res., 192 (1980) 163-176.

32 Chen, T. C., Cote, T. E. and Kebabian, J. W., Endogenous components of the striatum confer dopamine-sensitivity upon adenylate cyclase activity: the role of endogenous guanyl nucleotides, Brain Res., 181 (1980) 139-149.

33 Cherubini, E. and Anchors, J. M., Effects of nigral and cortical stimulation on cyclic AMP in the caudate nucleus of the cat, Neuropharmacology, 19 (1980) 111-115.

34 Cole, S. O., Brain mechanisms of amphetamine-induced anorexia, locomotion, and stereotypy: a review, Neurosci. Biobehav. Rev., 2 (1978) 89-100.

35 Cools, A. R., The puzzling 'cascade' of multiple receptors for dopamine. An appraisal of the current situation. Trends pharmacol. Sci., 2 (1981) 178-183.

36 Cooper, B. R., Breese, G. R., Grant, L. D. and Howard, J. L., Effects of 6-hydroxydopamine treatments on active avoidance responding: evidence for involvement of brain dopamine, J. Pharmacol. exp. Ther., 185 (1973) 358-370.

37 Cooper, B. R., Howard, J. L., Grant, L. D., Smith, R. D. and Breese, G. R., Alteration of avoidance and ingestive behavior after destruction of central catecholamine pathways with 6-hydroxydopamine, Pharmacol. Biochem. Be- hav., 2 (1974) 639-649.

38 Costa, E. and Garattini, S. (Eds.), Amphetamine and Related Compounds, Raven Press, New York, 1970.

39 Costall, B. and Naylor, R. J., The behavioral effects of dopamine applied intracerebrally to areas of the mesolimbic system, Europ. J. Pharmacol, 32 (1975) 87-92.

40 Costall, B. and Naylor, R. I., A comparison of the abilities of typical neuroleptic agents and of thioridazine, clozapine, sulpiride and metoclopramide to antagonize the hyperactivity induced by dopamine applied intracerebrally to areas of the extrapyramidal and mesolimbic systems, Europ. J. Pharmacol., 40 (1976) 9-19.

41 Costall, B., Naylor, R. J., Cannon, J. G. and Lee, T., Differentiation of the dopamine mechanism mediating stereotyped behaviour and hyperactivity in the nucleus accumbens and caudateputamen, J. Pharm. Pharmacol., 29 (1977) 337-342.

42 Costall, B. and Naylor, R. J., Behavioural aspects of dopamine agonists and antagonists. In A. S. Horn, J. Korf and B. H. C. Westerink (Eds.), The Neurobiology of Dopamine, Academic Press, London, 1979, pp. 555-576.

43 Creese, I. and Iversen, S. D., The role of forebrain dopamine systems in amphetamine-induced stereotyped behavior in the rat, Psychopharmacology, 39 (1974) 345-357.

44 Cross, A. J., Crow, T. J. and Owen, F., ${ }^{3} \mathrm{H}-$ Flupenthixol binding in postmortem brains of schizophrenics: evidence for a selective increase in dopamine D2 receptors, Psychopharmacology, 74 (1981) 122-124.

45 Crow, T. J., Cross, A. J., Johnstone, E. C., Longden, A., Owen, F., and Ridley, R. M., Time course of the antipsychotic effect in schizophrenia and some changes in postmortem brain and their relation to neuroleptic medication. In F. Cattabeni, G. Racagni, P. F. Spano, and E. Costa (Eds.), Long-term Effects of Neuroleptics, Raven Press, New York, 1980, pp. 495-503.

46 Davidson, A. B. and Weidley, E., Differential effects of neuroleptic and other psychotropic agents on acquisition of avoidance in rats, Life Sci., 18 (1976) 1279-1284.

47 Davis, W. M. and Smith, S. G., Effect of haloperidol in (+)-amphetamine self-administration, J. Pharm. Pharmacol., 27 (1975) 540-541.

48 Davis, W. M. and Smith, S. G., Catecholaminergic mechanisms of reinforcement: direct asessment by drug self-administration, Life Sci., 20 (1977) 483-492.

49 DeWit, H. and Wise, R. A., Blockade of cocaine reinforcement in rats with the dopamine receptor blocker pimozide, but not with noradrenergic blockers phentolamine or phenoxybenzamine, Canad. J. Psychol,, 31 (1977) 195-203.

50 Dill, R. E., Jones, D. L., Gillin, J. C. and Murphy, G., Comparison of behavioral effects of systemic L-DOPA and intracranial dopamine in mesolimbic forebrain of nonhuman primates, Pharmacol. Biochem. Behav., 10 (1979) 711-716.

51 Deutsch, J. A. and Rogers, J. B., Cholinergic excitability and memory: animal studies and their clinical implications. In K. L. Davis and P. A. Berger (Eds.), Brain Acetylcholine and Neuropsychiatric Disease, Plenum Press, New York, 1979, pp. 175-204.

52 Ehlert, F. J., Roeske, W. R. and Yamamura, H. I., Striatal muscarinic receptors: regulation by dopaminergic agonists, Life Sci., 28 (1981) 2441-2448.

53 Ettenberg, A., Cinsavich, S. A. and White, N., Perform- 
ance effects with repeated-response measures during pimozide-produced dopamine receptor blockade, Pharmacol. Biochem. Behav., 11 (1979) 1-5.

54 Ettenberg, A., Koob, G. F. and Bloom, F. E., Response artifact in the measurement of neuroleptic-induced anhedonia, Science, 213 (1981) 357-359.

55 Fallon, J. H., Riley, J. N. and Moore, R. Y., Substantia nigra dopamine neurons: separate populations project to neostriatum and allocortex, Neurosci. Lett., 7 (1978) $157-162$.

56 Farley, 1. J., Price, K. S. and Hornykiewicz, O., Dopamine in the limbic regions of the human brain: normal and abnormal. In E. Costa and G. L. Gessa (Eds.), Nonstriatal Dopaminergic Neurons, Raven Press, New York, 1977, pp. 57-64.

57 Feeney, D. M. and Wier, C. S., Sensory neglect after lesions of substantia nigra or lateral hypothalamus: differential severity and recovery of function, Brain Res., 178 (1979) 329-346.

58 Fibiger, H. C., The organization and some projections of cholinergic neurons of the mammalian forebrain, Brain Res. Rev., 4 (1982) 327-388.

59 Fibiger, H. C. and Phillips, A. G., Retrograde amnesia after electrical stimulation of the substantia nigra: mediation by the dopaminergic nigro-neostriatal bundle, Brain Res., 116(1976) 23-33.

60 Fibiger, H. C. and Phillips, A. G., Dopamine and the neural mechanisms of reinforcement. In A. S. Horn, J. Korf, and B. H. C. Westerink (Eds.), The Neurobiology of Dopamine, Academic Press, London, 1979, pp. 597-615.

61 Fibiger, H. C., Phillips, A. G. and Zis, A. P., Deficits in instrumental responding after 6-hydroxydopamine lesions of the nigro-neostriatal dopaminergic projection, Phatmacol. Biochem. Behav., 2 (1974) 87-96.

62 Fibiger, H. C., Zis, A. P. and Phillips, A. G., Haloperidolinduced disruption of conditioned avoidance responding: attenuation by prior training or by anticholinergic drugs, Europ. J. Pharmacol., 30 (1975) 309-314.

63 Fink, J. S. and Smith, G. P., Mesolimbic and mesocortical dopaminergic neurons are necessary for normal exploratory behavior in rats, Neurosci. Lett., 17 (1980) 61-65.

64 Fouriezos, G. and Wise, R. A., Pimozide-induced extinction of intracranial self-stimulation: response patterns rule out motor performance deficits, Brain Res., 103 (1976) $377-380$.

65 Fouriezos, G., Hansson, P. and Wise, R. A., Neurolepticinduced attenuation of brain stimulation reward in rats, $J$. comp. physiol. psychol., 92 (1978) 661-671.

66 Fray, P. J., Sahakian, B. J., Robbins, T. W., Koob, G. F. and Iversen, S. D., An observational method for quantifying the behavioural effects of dopamine agonists: Contrasting effects of D-amphetamine and apomorphine, $P_{s y}$ chopharmacology, 69 (1980) 253-259.

67 Franklin, K. B. J. and McCoy, S. N., Pimozide-induced extinction in rats: stimulus control of responding rules out motor deficit, Pharmacol. Biochem. Rehav., 11 (1979) $71-75$

68 Friedman, A. H, and Piepho, R. W., Effect of photoperiod reversal on twenty-four hour patterns for dopamine levels in the corpus striatum and upper and lower brainstem of the rat, Int. J. Chronobiol., 6 (1979) 57-65.

69 Fuster, J. M., The Prefrontal Cortex, Raven Press, New York, 1980.

70 Garcia, J. and Koelling, R. A., Relation of cue to conse- quence in avoidance learning, Psychon. Sci., 4 (1966) $123-124$.

71 Gerber, G. J., Sing, J. and Wise, R. A., Pimozide attenuates lever pressing for water reinforcement in rats, Pharmacol. Biochem. Behav., 14 (1981) 201-205.

72 Gray, T. and Wise, R. A., Effects of pimozide on lever pressing behavior maintained on an intermittent reinforcement schedule, Pharmacol. Biochem. Behav., 12 (1980) 931-935.

73 Greengard, P., Cyclic Nucleotides, Phosphorylated Pro teins, and Neuronal Function, Raven Press, New York, 1978.

74 Harvey, J. A. and Gormezano, I., Effects of haloperidol and pimozide on classical conditioning of the rabbit nictitating membrane response, J. pharmacol. exp. Ther., 218 (1981) 712-719.

75 Hartzell, H. C., Physiological consequences of muscarinic receptor activation, Trends pharmacol. Sci., 3 (1982) 213-214.

76 Hassler, R., Striatal control of locomotion, intentional actions and of integrating and perceptive activity, $J$. neurol. Sci., 36 (1978) 187-224.

77 Hedreen, J. C., Corticostriatal cells identified by the peroxidase method, Neurosci. Lett., 4 (1977) 1-7.

78 Heffner, T. G., Hartman, J. A. and Seiden, L. S., Feeding increases dopamine metabolism in the rat brain, Science, 208 (1980) 1168-1170.

79 Heffner, T. G., Luttinger, D., Martman, J. A. and Seiden, L. $S$., Regional changes in brain catecholamine turnover in the rat during performance on fixed ratio and variable interval schedules of reinforcement, Brain Res., 214 (1981) 215-218.

80 Heffner, T. G. and Seiden, L. S., Synthesis of catecholamines from $\left[{ }^{3} \mathrm{H}\right]$-tyrosine in brain during the performance of operant behavior, Brain Res., 183 (1980) 403-419.

81 Heimer, L., Switzer, R. D. and Van Hoesen, G. W., Ventral striatum and ventral pallidum: components of the motor system? Trends Neurosci., 5 (1982) 83-87.

82 Heimer, L. and Wilson, R. D., The subcortical projections of the allocortex: similarities in the neural associations of the hippocampus, the piriform cortex, and the neocortex. In M. Santini (Ed.), Golgi Centenial Symposium Proceedings, Raven Press, New York, 1975, pp. 177-193.

83 Hill, R. T., Facilitation of conditioned reinforcement as a mechanism of psychomotor stimulation. In E. Costa and S. Garattini (Eds.), Amphetamines and Related Compounds, Raven Press, New York, 1970, pp. 781-795.

84 Hinson, R. E. and Poulos, C. X., Sensitization to the behavioral effects of cocaine: modulation by Pavlovian conditioning, Pharmacol. Biochem. Behav., 15 (1981) $559-562$.

85 Hornykiewicz, O., Brain dopamine in Parkinson's disease and other neurological disturbances. In A. S. Horn, J. Korf and B. H. C. Westerink (Eds.), The Neurobiology of Dopamine, Academic Press, London, 1979, pp. 633-654.

86 Hunt, H. F., Some effects of drugs on classical (type s) conditioning, Ann. NY Acad. Sci., 65 (1956) 258-267.

$87 \mathrm{Hyttel}, \mathrm{J}$., Further evidence that ${ }^{3} \mathrm{H}$-Cis (Z) flupenthixol binds to the adenylate cyclase-associated receptor (D-1) in rat corpus striatum, Psychopharmacology, 67 (1980) $107-109$.

88 Imperato, A., Porceddu, M. L., Morelli, M., Faa, G. and Di Chiara, G., Role of dorsal mesencephalic reticular for- 
mation and deep layers of superior colliculus as out-put stations for turning behaviour elicited from the substantia nigra pars reticulata, Brain Res., 216 (1981) 437-443.

89 Irwin, S. and Armstrong, P. M., Conditioned locomotor response with drug as the unconditioned stimulus: individual differences, Neuropsychopharmacology, 2 (1961) 151-157.

90 Isaacson, R. L., Yongue, B. and McClearn, D., Dopamine agonists: their effects on locomotion and exploration, Behav. Biol., 23 (1978) 163-179.

91 Iversen, S. D. and Koob, G. F., Behavioral implications of dopaminergic neurons in the mesolimbic system. In $\mathrm{E}$. Costa and G. L. Gessa (Eds.), Nonstriatal Dopaminergic Neurons, Raven Press, New York, 1977, pp. 209-214.

92 Jackson, P. M., Anden, N.-E. and Dahlstrom, A., A functional effect of dopamine in the nucleus accumbens and in some other dopamine-rich parts of the rat brain, Psychopharmacology, 45 (1975) 139-149.

93 Joseph, M. H., Frith, C. D. and Waddington, J. L., Dopaminergic mechanisms and cognitive deficit in schizophrenia, Psychopharmacology, 63 (1979) 273-280.

94 Joyce, J. N., Davis, R. E. and Van Hartesveldt, C. V., Behavioral effects of unilateral dopamine injection into dorsal or ventral striatum, Europ. J. Pharmacol, 72 (1981) 1-10.

95 Kandel, E. R., Cellular insights into behavior and learning. In Harvey Lecture Series, Academic Press, New York, 1979, pp. 19-92.

$96 \mathrm{Katz}, \mathrm{R}$. J, , The temporal structure of motivation IV: a reexamination of extinction effects in intracranial reward, Behav. neural Biol., 32 (1981) 191-200.

97 Kebabian, J. W. and Calne, D. B., Multiple receptors for dopamine, Nature (Lond.), 277 (1979) 93-96.

98 Keller, R. W., Zigmond, M. I. and Stricker, F. M., Changes in striatal dopamine release following various stimuli as monitored by in vivo voltammetry, Soc. Neurosci. Abstr., 8(1982) 892.

99 Kelly, P. H., Seviour, P. W. and Iversen, S. D., Amphetamine and apomorphine responses in the rat following 6-OHDA lesions of the nucleus accumbens septi and corpus striatum, Brain Res., 94 (1975) 507-522.

100 Kemp, J. M. and Powell. T. P. S., The connexions of the striatum and globus pallidus: synthesis and speculation, Phil. Trans. B, 262 (1971) 441-457.

101 Kimura, H., McGeer, P. L., Peng, J. H. and McGeer, E. G., The central cholinergic system studied by choline acetyltransferase immunohistochemistry in the rat, $J$. comp. Neurol., 200 (1981) 151-201.

102 Koob, G. F., Fray, P. J. and Iversen, S. D., Self-stimulation at the lateral hypothalamus and locus coeruleus after specific unilateral lesions of the dopamine system, Brain Res., 14 (1978) 123-140.

103 Koob, G. F., Riley, S. I., Smith, S. C. and Robbins, T. W., Effects of 6-hydroxydopamine lesions of the nucleus accumbens septi and olfactory tubercle on feeding, locomotor activity, and amphetamine anorexia in the rat, $J$. comp. physiol. psychol., 92 (1978) 917-927.

104 Koob, G. F., Stinus, L. and LeMoal, M., Hyperactivity and hypoactivity produced by lesions to the mesolimbic dopamine system, Behav. Brain Res., 3 (1981) 341-359.

105 Krayniak, P. F, Meibach, R. C. and Siegel, A., A projection from the entorhinal cortex to the nucleus accumbens in the rat, Brain Res., 209 (1981) 427-431.

106 Krieger, N. R., Localization of dopamine-sensitive adeny- late cyclase within the rat olfactory tubercle, Brain Res., 183 (1980) 383-391.

107 Lai, H., Carino, M. A., Sperry, R. and Horita, A., Effects of microinjection of 2-chloro-11 (2-dimethylaminoetho$\mathrm{xy}$ )-dibenzo $[\mathrm{b}, \mathrm{f}]$-thiepine (zotepine), thioridazine and haloperidol into the striatum and nucleus accumbens on stereotypic behaviour and motor activity, J. Pharm. Pharmacol., 33 (1981) 252-254.

108 Lee, T. and Seeman, P., Elevation of brain neuroleptic/ dopamine receptors in schizophrenia, Amer. J. Psychiat., 137 (1980) 191-197.

109 LeMoal, M., Galey, D. and Cardo, B., Behavioral effects of local injection of 6-hydroxydopamine in the medial ven. tral tegmentum in the rat. Possible role of the mesolimbic dopaminergic system, Brain Res., 88 (1975) 190-194.

110 Lenard, L. G. and Beer, B., 6-hydroxydopamine and avoidance: possible role of response suppression, Pharmacol. Biochem. Behav., 3 (1975) 873-878.

111 Levine, T. E., McGuire, P. S., Heffner, T. G. and Seiden, L. S., DRL performance in 6-hydroxydopamine-treated rats, Pharmacol. Biochem. Behav., 12 (1980) 287-291.

112 Libet, B., Dopaminergic synaptic processes in the superior cervical ganglion: models for synaptic actions. In A. S. Horn, J. Korf and B. H. C. Westerink (Eds.), Neurobiology of Dopamine, Academic Press, New York, 1979, pp. 453-474.

113 Libet, B., Kobayashi, H. and Tanaka, T., Synaptic coupling into the production and storage of a neuronal memory trace, Nature (Lond.), 258 (1975) 155-157.

114 Lindvall, O., Dopamine pathways in the rat brain. In A.S. Horn, J. Korf and B. H. C. Westerink (Eds.), The Neurobiology of Dopamine, Academic Press, London, 1979, pp. 319-342.

115 Lindvall, O. and Björklund, A., Anatomy of the dopaminergic neuron systems in the rat brain. In P. J. Roberts, G. N. Woodruff and L. L. Iverson (Eds.), Dopamine, Raven Press, New York, 1978, pp. 1-24.

116 Lindvall, O., Björklund, A. and Divac, I., Organization of catecholamine neurons projecting to the frontal cortex in the rat, Brain Res., 142 (1978) 1-24.

117 Lipton, M. A. and Nemeroff, C. B., An overview of the biogenic amine hypothesis of schizophrenia. In W. E. Fann, I. Karacan, A. Pokorny and R. L. Williams (Eds.), Phenomenology and Treatment of Schizophrenia, Spectrum Publications, New York, 1978.

118 Lyon, M. and Robbins, T. W., The action of central nervous system stimulant drugs: A general theory concerning amphetamine affects. In W. B. Esssman and L. Valzelli (Eds.), Current Developments in Psychopharmacology Vol. 2, Spectrum, New York, 1975, pp. 79-163.

119 Mackintosh, J. J., The Psychology of Animal Learning, Academic Press, New York, 1974, pp. 222-233.

120 Matthysse, S., Schizophrenia: Relationship to dopamine transmission, motor control, and feature extraction. In F. O. Schmitt and F. G. Worden (Eds.), The Neurosciences: Third Study Program, MTT Press, Cambridge, MA, 1974, pp. $733-737$.

121 Marshall, J. F., Somatosensory inattention after dopamine-depleting intracerebral 6-OHDA injections: spontaneous recovery and pharmacological control, Brain Res., 177 (1979) 311-324.

122 Marshall, J. F., Levitan, D. and Stricker, E. M., Activation-induced restoration of sensorimotor functions in rats with dopamine-depleting brain lesions, $J$. comp. physiol. 
Psychol., 90 (1976) 536-546.

123 Marshall, J. F., Richardson, J. S. and Teitelbaum, P., Nigrostriatal bundle damage and the lateral hypothalamic syndrome, J. comp. physiol. Psychol., 87 (1974) 808-830.

124 Mason, S. T., Beninger, R. J., Fibiger, H. C. and Phillips, A. G., Pimozide-induced suppression of responding: evidence against a block of food reward, Pharmacol. Biochem. Behav., 12 (1980) 917-923.

125 McGeer, P. L., McGeer, E. G. and Suzuki, J. S., Aging and extrapyramidal function, Arch. Neurol., 34 (1976) 33-35.

$126 \mathrm{McGhie}$ A., Attention and perception in schizophrenia. In B. A. Maher, (Ed.), Contributions to the Psychopathology of Schizophrenia, Academic Press, New York, 1977, pp. 57-96.

127 Miller, J. D., Sanghera, M. K. and German, D. C., Mesencephalic dopaminergic unit activity in the behaviorally conditioned rat, Life Sci., 29 (1981) 1255-1263.

128 Mogenson, G. and Cioe, J., Central reinforcement: a bridge between brain function and behavior. In W. K. Honig and J. E. R. Staddon, Handbook of Operant Behavior, Prentice-Hall, Englewood Cliffs, NJ, 1977, pp. 570-595.

129 Mogenson, G. J., Takigawa, M., Robertson, A. and Wu, M., Self-stimulation of the nucleus accumbens and ventral tegmental area of Tsai attenuated by microinjections of spiroperidol into the nucleus accumbens, Brain Res., 171 (1979) 247-259.

130 Morelli, M., Imperator, A., Porceddu, M. L. and Di Chiara, G., Role of dorsal mesencephalic reticular formation and deep layers of superior colliculus in turning behaviour elicited from the striatum, Brain Res., 215 (1981) 337-341.

131 Myers, R., and Mora, F., In vivo neurochemical analysis, by push-pull perfusion, of the mesocortical dopaminergic system of the rat during self-stimulation, Brain Res. Bull,, 2 (1977) 105-112.

132 Nauta, H. J. W., A proposed conceptual reorganization of the basal ganglia and telencephalon, Neuroscience, 4 (1979) 1875-1881.

133 Nauta, W. J. H., Smith, G. P., Faull, R. L. M. and Domesick, V. B., Efferent connections and nigral afferents of the nucleus accumbens septi in the rat, Neuroscience, 3 (1978) 385-401.

134 Niemegeers, C. J. E., Verbruggen, F. J. and Janssen, P. A. J., The influence of various neuroleptic drugs on shock avoidance responding in rats, Psychopharmacologia, 16 (1969) 161-174.

135 Oades, R. D., Impairments of search behaviour in rats after haloperidl treatment, hippocampal of neocortical damage suggest a mesocorticolimbic role in cognition, Biol. Psychiat., 12 (1981) 77-85.

136 Otterson, O. P., Connections of the amygdala of the rat. IV. Corticoamygdaloid and intraamygdaloid connections as studied with axonal transport of horseradish peroxidasc, J. comp. Neurol, 205 (1982) 30-48.

137 Panula, P. and Rechardt, L., Ultrastructural demonstration of adenylate cyclase activity in the rat neostriatum. Neuroscience, 4 (1979) 779-788.

138 Perlow, M. J., Gordon, E. K., Ebert, M. E., Hoffman, H. J. and Chase, T. N., The circadian variation in dopamine in the subhuman primate, $J$. Neurochem., 28 (1977) 1381-1383.

139 Phillips, A. G., Carter, D. A. and Fibiger, H. C., Dopaminergic substrates of intracranial self-stimulation in the caudate-putamen, Brain Res., 104 (1976) 221-232.

140 Phillips, A. G. and Clouston, R., Disruption of one-trial appetitive learning and passive avoidance following stimulation of the substantia nigra, pars compacta, Science, 181 (1973) 83-86.

141 Phillips, A. G. and Fibiger, H. C., Decreased resistance to extinction after haloperidol: implications for the role of dopamine in reinforcement, Pharmacol. Biochem. Behav., 10 (1979) 751-760.

142 Pickens, R. W. and Crowder, W. F., Effects of CS-US interval on conditioning of drug response, with assessment of speed of conditioning. Psychopharmacology, 11 (1967) 88-94.

143 Pijnenburg, A. J. J., Honig, W. M. M., Van Der Heyden, J. A. M. and Van Rossum, J. M., Effects of chemical stimulation of the mesolimbic dopamine system upon locomotor activity, Europ. J. Pharmacol., 35 (1976) 45-58.

144 Pijnenburg, A. J. J., Honig, W. M. M. and Van Rossum, J. M., Inhibition of D-amphetamine-induced locomotor activity by injection of haloperidol into the nucleus accumbens of the rat, Psychopharmacology, 41 (1975) 87-95.

145 Pinel, J. P. J. and Treit, D, Burying as a defensive response in rats, J. comp. physiol. Psychol, 92 (1978) 708-712.

146 Posluns, D., An analysis of chlorpromazine-induced suppression of the avoidance response, Psychopharmacology, 3 (1962) 361-373.

147 Post, R. M., Lockfeld, A., Squillace, K. M. and Contel, N. R., Drug-environment interaction: context dependency of cocaine-induced behavioral sensitization, Life Sci., 28 (1980) 755-760.

148 Price, M. T. C. and Fibiger, H. C., Discriminated escape learning and response to electric shock after 6-hydroxydopamine lesions of the nigro-neostriatal dopaminergic projection, Pharmacol. Biochem. Behav., 3 (1975) 285-290.

149 Ranje, C. and Ungerstedt, U., Discriminative and motor performance in rats after interference with dopamine neurotransmisson with spiroperidol, Europ. J. Pharmacol., 43 (1977) $39-46$.

150 Ranje, $C$, and Ungerstedt, $U$., Lack of acquisition in dopamine denervated animals tested in an underwater Y-maze, Brain Res., 134 (1977) 95-111.

151 Rescorla, R. A. and Solomon, R. L., Two process leáning theory: Relationships between Pavlovian conditioning and instrumental learning, Psychol. Rev., 74 (1967) $151-182$.

152 Richter, D., Clues to the causation of schizophrenia. In G. Hemmings and W. A. Hemmings (Eds.), The Biological Basis of Schizophrenia, University Park Press, Baltimore, MD, 1978, pp. 55-61

153 Robbins, T. W., The potentiation of conditioned reinforcement by psychomotor stimulant drugs. A test of Hill's hypothesis, Psychopharmacologia, 45 (1975) 103-114.

154 Robbins, T. W., Relationship between reward-cnhancing and stereotypical effects of psychomotor stimulant drugs, Nature (Lond.), 264 (1976) 57-59.

155 Robbins, 'I', W., The acquisition of responding with conditioned reinforcement: effects of pipradrol, methylphenidate, D-amphetamine, and nomifensine, Psychopharmacology, 58 (1978) 79-87.

156 Robbins, T. W. and Everitt, B. J., Functional studies of the central catecholamines, Int. Rev. Neurobiol., 23 (1982) 303-365. 
157 Robbins, T. W. and Koob, G. F., Pipradrol enhances reinforcing properties of stimuli paired with brain stimulation, Pharmacol. Biochem. Behav., 8 (1978) 219-222.

158 Robbins, T. W., Watson, B. A., Gaskin, M. and Ennis, C., Contrasting interactions of pipradrol, D-amphetamine, cocaine, cocaine analogues, apomorphine and other drugs with conditioned reinforcement, Psychopharmacology, 80 (1983) 113-119.

159 Roberts, D. C. S., Corcoran, M. E. and Fibiger, H. C., On the role of ascending catecholaminergic systcms in intravenous self-administration of cocaine, Pharmacol. Biochem. Behav., 6 (1977) 615-620.

160 Ross, S. and Schnitzer, S. B., Further support for a placebo effect in the rat, Psychol. Rep., 13 (1963) $461-462$.

161 Routtenberg, A. and Holzman, N., Memory disruption by electrical stimulation of substantia nigra, pars compacta, Science, 171 (1973) 83-86.

162 Routtenberg, A. and Kim, H.-J., The substantia nigra and neostriatum: substrates for memory consolidation. In $\mathrm{L}$. L. Butcher (Ed.), Cholinergic-Monoaminergic Interactions in the Brain, Academic Press, New York, 1978, pp. 305-334.

163 Sacks, O., Awakenings, Random House, New York, 1973.

164 Scheel-Krüger, J., Comparative studies of various amphetamine analogues demonstrating different interactions with the metabolism of the catecholamines in the brain, Europ. J. Pharmacol., 14 (1971) 47-59.

165 Schmidt, M. J., Perspectives on dopamine-sensitive adenylate cyclase in the brain. In G. C. Palmer (Ed.), Neuropharmacology of Cyclic Nucleotides, Urban Schwarzenberg, Baltimore, MD, 1979, pp. 1-52.

166 Schoener, E. P., Hager, P. J., Felt, B. T. and Schneider, D. R., Cyclic nucleotides in the rat neostriatum: push-pull perfusion studies, Brain Res., 179 (1979) 111-119.

167 Schutz, R. A., Barros Schutz, M. T., Orsingher, O. A. and Izquierdo, 1., Brain dopamine and noradrenaline levels in rats submitted to four different aversive behavioral tests, Psychopharmacology, 63 (1979) 289-292.

168 Schwab, R. S., Akinesia paradoxica, Electroenceph. clin. Neurophysiol., 31 (1972) 87-92.

169 Schwab, R. S. and Zeiper, I., Effects of mood, motivation, stress and alertness on the performance in Parkinson's disease, Psychiat. Neurol., 150 (1965) 345-357.

170 Seeman, P., Brain dopamine receptors, Pharmacol. Rev., 32 (1981) 229-313

171 Shaywitz, B. A., Yager, R. D. and Klopper, J. H., Selective brain dopamine depletion in developing rats: an experimental model of minimal brain dysfunction, Science, 191 (1976) 305-308.

172 Siegfried, B. and Bures, J., Conditioning compensates the neglect due to unilateral 6-OHDA lesions of substantia nigra in rats, Brain Res., 167 (1979) 139-155.

173 Simon, H., LeMoal, M. and Calas, A., Efferents and afferents of the ventral tegmental-A10 region studied after local injection of $\left[{ }^{3} \mathrm{H}\right]$-leucine and horseradish peroxidase, Brain Res., 178 (1979) 17-40.

174 Simon, H., Scatton, B. and LeMoal, M., Dopaminergic A10 neurons are involved in cognitive functions, Nature (Lond.), 286 (1980) 150-151.

175 Simon, J. R., Cortical modulation of cholinergic neurons in the striatum, Life Sci., 31 (1982) 1501-1508.

176 Snyder, S. H., Catecholamines in the brain as mediators of amphetamine psychosis, Arch. gen. Psychiat, 27 (1972) 169-179.

177 Snyder, S. H., The dopamine hypothesis of schizophrenia: Focus on the dopamine receptor, Amer. J. Psychiat., 133 (1976) 197-202.

178 Snyder, S. H., Dopamine receptors, neuroleptics, and schizophrenia, Amer. J. Psychiat., 138 (1981) 460-464.

179 Sokoloff, P., Martres, M. P. and Schwartz, J. C., Three classes of dopamine receptor (D-2, D-3, D-4) identified by binding studics with ${ }^{3} \mathrm{I}$-apomorphinc and ${ }^{3} \mathrm{H}$-dompcridone, Naunyn-Schmiedeberg's Arch. Pharmacol., 315 (1980) 89-102.

180 Solomon, P. R., Crider, A., Winkelmann, J. W., Turi, A., Kamer, R. M. and Kaplan, L. J., Disrupted latent inhibition in the rat with chronic amphetamine or haloperidolinduced supersensitivity: relationship to schizophrenic attention disorder, Biol. Psychiat., 16 (1981) 519-537.

181 Solomon, P. R. and Staton, D. M., Differential effects of microinjections of $\mathrm{D}$-amphetamine into the nucleus accumbens or the caudate putamen on rat's ability to ignore an irrelevant stimulus, Biol. Psychiat., 17 (1982) 743-756.

182 Spitzer, R. L., Williams, J. B. W. and Skodol, A. E., DSM-III: The major achievements and an overview, Amer. J. Psychiat., 137 (1980) 151-164.

183 Stricker, E. M., Cooper, P. H., Marshall, J. F. and Zigmond, M. J., Acute homeostatic imbalances reinstate sensorimotor dysfunctions in rats with lateral hypothalamic lesions, J. comp. physiol. Psychol., 93 (1979) 512-521.

184 Szostak, C., Tombaugh, T. N. and Tombaugh, J., Examination of the effects of pimozide on two conditional discrimination problems differing in levels of task complexity, Progr. Neuropharmacol., 5 (1981) 615-618.

185 Tarsy, L., Interactions between acetylcholine and dopamine in the basal ganglia. In K. L. Davis and P. A. Berger (Eds.), Brain Acetylcholine and Neuropsychiatric Disease, Plenum Press, New York, 1979, pp. 395-424.

186 Tassin, J.-P., Stinus, L., Simon, H., Blanc, G., Thierry, A.-M., LeMoal, M., Cardo, B. and Glowinski, J. Relationship between the locomotor hyperactivity induced by A10 lesions and the destruction of the frontocortical dopaminergic innervation in the rat, Brain Res., 141 (1978) 267-281 .

187 Teitelbaum, P., Shallert, T., DeRyck, M., Wishaw, I. Q. and Golani, I., Motor subsystems in motivated behavior. In R. F. Thompson, L. H. Hicks and V. B. Shvyrkov (Eds.), Neural Mechanisms of Goal-Directed Behavior and Learning, Academic Press, New York, 1980, pp. 127143.

188 Tilson, H. A. and Rech, R. H., Conditioned drug effects and absence of tolerance to D-amphetamine induced motor activity, Pharmacol. Biochem. Behav., 1 (1973) 149-153.

189 Tombaugh, T. N., Effects of pimozide on nondiscriminated and discriminated performance in the pigeon, $P s y$ chopharmacology, 73 (1981) 137-141.

190 Tombaugh, T. N., Anisman, H. and Tombaugh, J., Extinction and dopamine receptor blockade after intermittent reinforcement training: failure to observe functional equivalence, Psychopharmacology, 70 (1980) 19-28

191 Tombaugh, T. N., Ritch, M. A. and Shepherd, D. T., Effects of pimozide on accuracy of performance and distribution of correct responding on a simultaneous discrimination task in the rat, Pharmacol. Biochem. Behav., 13 (1980) 859-862. 
192 Tombaugh, T. N. Tombaugh, J. and Anisman, H.. Effects of dopamine receptor bluckade on alimentary behavtors: home cage food consumption, magazine training, operant acquisition, and performance, Psychopharmacolo$g y, 66$ (1979) $219-225$.

193 Trowill, J. A., Panksepp, J. and Gandelman, R., An incentive model of rewarding brain stimulation. Psychol. Rev., 76 (1969) 264-281.

194 Ungerstedt, U., Central dopamine mechanisms and behaviour. In A. S. Horn, J, Korf, and B. H. C. Westerink (Eds.), The Neurobiology of Dopamine, Academic Press, London, 1979, pp. 577-596.

195 Van Hoesen, G. W., Yeterian, E. H. and Lavizzo-Mou rey, R., Widespread corticostriate projections from temporal cortex of the rhesus monkey, J. comp. Neurol., 199 (1981) 205-219.

196 Van Kammen, D. P., The dopamine hypothesis of schizophrenia revisited, Psychoneuroendocrinology, 4 (1979) $37-46$.

197 Wachtel, H., Ahlenius, S. and Anden, N.-E., Effects of locally applied dopamine to the nucleus accumbens on the motor activity of normal rats and following methyltyrosine or reserpine, Psychopharmacology, 63 (1979) 203-206.

198 Wise, R. A., Catecholamine theories of reward: a critical review, Brain Res., 152 (1978) 215-247.

199 Wise, R. A., Brain dopamine and reward. In S. I. Cooper (Ed.), Theory in Psychopharmacology, Vol. I, Academic Press, London, 1981, pp. 103-122.

200 Wise, R. A., Neuroleptics and operant behavior: the anhedonia hypothesis, Behav, Brain Sci., 5 (1982) 39-88.

201 Wise, R. A. and Schwartz, H. V., Pimozide attenuates ac- quisition of lever-pressing for food in rats, Pharmacol Biochem. Behav., 15 (1981) 655-656.

202 Wise, R. A., Spindler, J., DeWit, H. and Gerber, G. J., Neuroleptic-induced 'anhedonia' in rats: pimozide blocks reward quality of food, Science, 201 (1978) 262-264.

203 Wise, R. A., Spindler, J. and Legault, L., Major attenuation of food reward with performance-sparing doses of pimozide in the rat, Canad. J. Psychol./Rev. Canad. Psy. chol, 32 (1978) 77-85

204 Yamamura, H. I., Kuhar, M. J., Greenberg, D. and Snyder, S. H., Muscarinic cholinergic receptor binding: regional distribution in monkey brain, Brain Res., 66 (1974) $541-546$.

205 Yim, C. Y. and Mogenson, G. J., Response of nucleus accumbens neurons to amygdala stimulation and its modification by dopamine, Brain Res., 239 (1982) 401-415.

206 Yokel, R. A. and Wise, R. A., Increased lever pressing for amphetamine after pimozide in rats: implications for a dopamine theory of reward, Science, 187 (1975) 547-549.

207 Yokel, R. A. and Wise, R. A., Attenuation of intravenous amphetamine reinforcement by central dopamine blockade in rats, Psychopharmacology, 48 (1976) 311-318.

208 Zarevics, P. and Setler, P. E., Simultaneous rate-independent and rate-dependent assessment of intracranial selfstimulation: evidence for the direct involvement of dopamine in brain reinforcement mechanisms, Brain Res., 169 (1979) 499-512.

209 Zis, A. P., Fibiger, H. C. and Phillips, A. G., Reversal by L-Dopa of impaired learning due to destruction of the dopaminergic nigro-neostriatal projection, Science, 185 (1974) 960-962. 